\title{
Glycinergic Input to the Mouse Basal Forebrain Cholinergic Neurons
}

\author{
Zsuzsanna Bardóczi, ${ }^{1,2}$ Balázs Pál, ${ }^{3}$ Áron Kőszeghy, ${ }^{3}$ Tamás Wilheim, ${ }^{1,6}$ @Masahiko Watanabe, ${ }^{4}$ László Záborszky, ${ }^{5}$ \\ Zsolt Liposits, ${ }^{1,6}$ and $\odot$ Imre Kalló ${ }^{1,6}$ \\ ${ }^{1}$ Laboratory of Endocrine Neurobiology, Institute of Experimental Medicine, HAS, 1083, Budapest, Hungary, 2 Semmelweis University, School of PH.D. \\ Studies, 1085, Budapest, Hungary, ${ }^{3}$ Department of Physiology, Faculty of Medicine, University of Debrecen, 4032, Debrecen, Hungary, ${ }^{4}$ Department of \\ Anatomy, Hokkaido University School of Medicine, Sapporo 060-8638, Japan, ${ }^{5} \mathrm{Center}$ for Molecular and Behavioral Neuroscience, Rutgers, Newark, \\ New Jersey 07102, and 'Department of Neuroscience, Faculty of Information Technology, Pázmány Péter Catholic University, 1083, Budapest, Hungary
}

The basal forebrain $(\mathrm{BF})$ receives afferents from brainstem ascending pathways, which has been implicated first by Moruzzi and Magoun (1949) to induce forebrain activation and cortical arousal/waking behavior; however, it is very little known about how brainstem inhibitory inputs affect cholinergic functions. In the current study, glycine, a major inhibitory neurotransmitter of brainstem neurons, and gliotransmitter of local glial cells, was tested for potential interaction with BF cholinergic (BFC) neurons in male mice. In the BF, glycine receptor $\alpha$ subunit-immunoreactive (IR) sites were localized in choline acetyltransferase (ChAT)-IR neurons. The effect of glycine on BFC neurons was demonstrated by bicuculline-resistant, strychnine-sensitive spontaneous IPSCs (sIPSCs; $0.81 \pm 0.25 \times 10^{-1} \mathrm{~Hz}$ ) recorded in whole-cell conditions. Potential neuronal as well as glial sources of glycine were indicated in the extracellular space of cholinergic neurons by glycine transporter type 1 (GLYT1)- and GLYT2-IR processes found in apposition to ChAT-IR cells. Ultrastructural analyses identified synapses of GLYT2-positive axon terminals on ChAT-IR neurons, as well as GLYT1-positive astroglial processes, which were localized in the vicinity of synapses of ChAT-IR neurons. The brainstem raphe magnus was determined to be a major source of glycinergic axons traced retrogradely from the BF. Our results indicate a direct effect of glycine on BFC neurons. Furthermore, the presence of high levels of plasma membrane glycine transporters in the vicinity of cholinergic neurons suggests a tight control of extracellular glycine in the BF.

Key words: axospinous; basal forebrain; cholinergic; glycine; glycine transporter; synapse

Significance Statement

Basal forebrain cholinergic (BFC) neurons receive various activating inputs from specific brainstem areas and channel this information to the cortex via multiple projections. So far, very little is known about inhibitory brainstem afferents to the BF. The current study established glycine as a major regulator of BFC neurons by (1) identifying glycinergic neurons in the brainstem projecting to the BF, (2) showing glycine receptor $\alpha$ subunit-immunoreactive (IR) sites in choline acetyltransferase (ChAT)-IR neurons, (3) demonstrating glycine transporter type 2 (GLYT2)-positive axon terminals synapsing on ChAT-IR neurons, and (4) localizing GLYT1-positive astroglial processes in the vicinity of synapses of ChAT-IR neurons. The effect of glycine on BFC neurons was demonstrated by bicuculline-resistant, strychnine-sensitive spontaneous IPSCs recorded in whole-cell conditions.

\section{Introduction}

Forebrain activation and cortical arousal/waking behavior are thought to be critically influenced by ascending pathways deriv-

\footnotetext{
Received 0ct. 30, 2016; revised Aug. 21, 2017; accepted Aug. 24, 2017.

Author contributions: B.P. and I.K. designed research; Z.B., B.P., A.K., and I.K. performed research; M.W. and I.K. contributed unpublished reagents/analytic tools; Z.B., B.P., A.K., T.W., and I.K. analyzed data; Z.B., B.P., L.Z., Z.L., and I.K. wrote the paper.

This research was supported by grants from the National Science Foundation of Hungary (OTKA K101326 to I.K., and OTKA K115984 to Z.L.), the National Brain Research Program of Hungary (KTIA_13_NAP-A-I/10 to B.P.), and National Institutes of Health/National Institute of Neurological Disorders and Stroke (NSO23945 to L.Z.). We thank Imre Farkas and János Szabadics for the critical reading of the manuscript, Adrienn Kovács for her valuable contribution, and Barna László for the excellent technical assistance.

The authors declare no competing financial interests.
}

ing from the brainstem (Buzsaki et al., 1988; Steriade and Timofeev, 2002; Sutcliffe and de Lecea, 2002; Zaborszky and Duque, 2003; Saper et al., 2005; Datta and Maclean, 2007; Fuller et al., 2011; Luppi et al., 2013). These axons form a ventral pathway targeting the basal forebrain $(\mathrm{BF})$, including its cholinergic corticopetal neurons and hypocretin/MCH neurons in the hypo-

Correspondence should be addressed to Dr. Imre Kalló, Laboratory of Endocrine Neurobiology, Institute of Experimental Medicine, Hungarian Academy of Sciences, P.0. Box 67, 1450, Budapest, Hungary. E-mail: kallo@koki.hu.

Á. Köszeghy's present address: Department of Cognitive Neurobiology, Center for Brain Research, Medical University of Vienna, 1090 Vienna, Austria.

DOl:10.1523/JNEUROSCI.3348-16.2017

Copyright $\odot 2017$ the authors $\quad 0270-6474 / 17 / 379534-16 \$ 15.00 / 0$ 
thalamus and a dorsal pathway innervating thalamic nuclei. The dorsal pathway contains glutamatergic and cholinergic projections from the mesopontine tegmentum (Luppi et al., 2013). Catecholaminergic and glutamatergic ascending axons have been suggested to contact cholinergic neurons in the BF and GABAergic neurons in the ventrolateral preoptic nucleus (Luppi et al., 2013; Zaborszky et al., 2015). In addition, it has been shown that hypocretin axons synapse with septal cholinergic neurons and depolarize them (Wu et al., 2004). Recently a glycinergic pathway has been described deriving from the pontine reticular formation and targeting the intralaminar thalamic nuclei; optogenetic stimulation of the contributing cell population in mice evoked behavioral arrest and transient interruption of awake cortical activity (Giber et al., 2015).

A potential role for glycine in the BF has also been postulated in our previous study (Bardóczi et al., 2013) based on the presence of membrane glycine transporter type 1 (GLYT1) and GLYT2. GLYTs, depending on their location, have distinct functions at glycinergic synapses. GLYT2 provides glycine for the refilling of presynaptic vesicles of glycinergic neurons (Gomeza et al., 2003), whereas GLYT1 ensures the removal of glycine from the synaptic cleft into glial cells, leading to the termination of glycine-mediated neurotransmission. In addition, GLYT1 is also present in certain glutamatergic neurons and regulates the concentration of glycine at excitatory synapses containing NMDA receptors, which are known to require glycine as a coagonist (Eulenburg et al., 2005).

$\mathrm{BF}$ areas [i.e., the medial septum (MS), vertical limb of the diagonal band of Broca (VDB), horizontal limb of the diagonal band of Broca (HDB), ventral pallidum (VP), and the substantia innominate (SI)] contain a heterogeneous collection of cholinergic, GABAergic, glutamatergic projection neurons, and various interneurons (for review, see Zaborszky et al., 2015). The large cholinergic neurons are wake-promoting neurons, as are the glutamatergic and parvalbumin-positive GABAergic neurons, which are more active during wakefulness and rapid eye movement (REM) sleep (wake/REM active) than during non-REM (NREM) sleep. Optogenetic activation of these neurons rapidly induces wakefulness, contrasting with somatostatin-positive GABAergic neurons, the stimulation of which promotes NREM sleep (Xu et al., 2015). However, chemogenetic activation of BF cholinergic or glutamatergic neurons in behaving mice has no effect on total wakefulness. In contrast, similar chemogenetic activation of BF GABAergic neurons produces sustained wakefulness and highfrequency cortical rhythms (Anaclet et al., 2015). Other data suggest that specific types of $\mathrm{BF}$ neurons play distinct roles in cortical (Kim et al., 2015) and hippocampal oscillations (Sotty et al., 2003) or in inducing hippocampal LTP or LTD (Gu and Yakel, 2011). Thus, it is very important to define which types of BF neurons are regulated by glycine.

The aim of the present study was to define whether the function of BF cholinergic neurons is influenced by glycine. Confocal and electron microscopic studies were used to characterize the morphological relationship of choline acetyltransferase (ChAT)immunoreactive (IR) neurons with GLYT1- and/or GLYT2-IR cellular processes. In addition, in vitro patch-clamp electrophysiology was used to demonstrate the effect of glycine on cholinergic neurons. Our results indicate that glycine has a direct influence on $\mathrm{BF}$ cholinergic (BFC) neurons by demonstrating (1) bicuculline-resistant, strychnine-sensitive spontaneous IPSCs; (2) synaptic connections between glycinergic and cholinergic neurons; and (3) strong presence of glycine transporters in glial and neuronal processes in the vicinity of cholinergic neu- rons. The primary origin of glycinergic axons of the $\mathrm{BF}$ is the raphe magnus and its neighboring reticular formation of the pons.

\section{Materials and Methods}

Animals

Wild-type (CD1, Charles River; $n=21$ ) and transgenic male mice expressing the fluorescent reporter proteins eGFP (GLYT2-eGFP, Zeil-

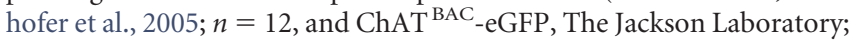
$n=3)$, or tdTomato ((ChAT ${ }^{\mathrm{CRE}_{-}}$-tdTomato, $\left.n=26\right)$, generated by crossbreeding of ChAT-CRE mice (Rossi et al., 2011, http://www.informatics. jax.org/reference/J:114556; JAX mice catalog \#006410; $n=2$ ) and floxed-stop-tdTomato reporter mice (Madisen et al., 2010, JAX mice catalog $\# 007905 ; n=6)$ ) were used. Mice ( $1-3$ months old, $25-30$ g body weight) were housed under controlled lighting (12 h light/dark cycle; lights on at 7:00 A.M., zeitgeber time 0$)$ and temperature $\left(22 \pm 2^{\circ} \mathrm{C}\right)$ with access to food and water ad libitum. Studies were performed with permission from the Animal Welfare Committee of the Institute of Experimental Medicine (No. 2285/003) and Debrecen University (No. 6/2011/DE MÁB and 5/2015/DEMÁB) and in accordance with legal requirements of the European Community (Decree 86/609/EEC). Surgery was performed on animals under deep anesthesia induced by an intraperitoneally injected cocktail of ketamine ( $25 \mathrm{mg} / \mathrm{kg}$ body weight), Xylavet ( $5 \mathrm{mg} / \mathrm{kg}$ body weight), and Pipolphen $(2.5 \mathrm{mg} / \mathrm{kg}$ body weight) in saline.

\section{Anatomical studies}

Tissue preparation. Mice were perfused transcardially with PBS $(0.1 \mathrm{M})$ containing $4 \%$ paraformaldehyde (PFA). The brains were postfixed in $2 \% \mathrm{PFA} / \mathrm{PBS}$ solution for $24 \mathrm{~h}$ at $4^{\circ} \mathrm{C}$ and cryoprotected overnight in $25 \%$ sucrose, and $25-\mu \mathrm{m}$-thick coronal sections were cut from a block of the basal forebrain expanding between bregma +1.3 and $-1.3 \mathrm{~mm}$ on a freezing microtome. The sections were divided into three sequential pools ( $\sim 30-35$ sections in each set, with $50 \mu \mathrm{m}$ gaps between consecutive sections) and stored in antifreeze solution [ $30 \%$ ethylene glycol; $25 \%$ glycerol; 0.05 м phosphate buffer (PB); $\mathrm{pH} 7.4]$ at $-20^{\circ} \mathrm{C}$ until use. For mapping the immunolabeled cells and cellular profiles, a set of sections from each brain was Nissl counterstained, photographed, and matched with the corresponding atlas figures. After the endogenous peroxidase activity had been quenched with $0.5 \%$ hydrogen peroxide ( $10 \mathrm{~min}$ ), sections were permeabilized with $0.5 \%$ Triton X-100 (catalog \#23,472-9, Sigma-Aldrich; $20 \mathrm{~min}$ ). Finally, $2 \%$ normal horse serum (NHS) was applied (for $20 \mathrm{~min}$ ) to reduce nonspecific antibody binding. Subsequent treatments and interim rinses in PBS $(3 \times$ for $5 \mathrm{~min})$ were performed at room temperature, except for incubation in the primary antibody or fluorochrome conjugate, which took place at $4^{\circ} \mathrm{C}$.

Double-labeling for GLYT1 or GLYT2 and ChAT immunoreactivity. Sections from the BF region of $\mathrm{CD} 1$ mice were incubated in goat antiGLYT1 (1:10,000; catalog \#AB1770, Millipore; RRID:AB_90893) or rabbit anti-GLYT2 [1 $\mu \mathrm{g} / \mathrm{ml}$; \#N30aa, a gift from M.W. (Hondo et al., 2011); RRID:AB_2571606] primary antibodies. GLYT1 and GLYT2 immunoreactivities were visualized with biotinylated donkey anti-goat IgG (dilution, 1:500; 2 h; catalog \#705-065-147, Jackson ImmunoResearch) or biotinylated donkey anti-rabbit IgG (dilution, 1:500; $2 \mathrm{~h}$; catalog \#711065-152, Jackson ImmunoResearch) and Vectastain ABC Elite solution (dilution 1:1000; 1.5 h; PK-6100, Vector Laboratories), then the signal was detected with nickel-intensified diaminobenzidine (NiDAB). The $\mathrm{NiDAB}$ reaction product was further intensified by the application of a special physical developer producing silver precipitate on NiDAB, which was then stabilized with gold toning (silver-gold intensified NiDAB, SGINiDAB; Kalló et al., 2001), similar to the method described before for DAB (Liposits et al., 1984). Due to the relatively large difference in the argyrophilia of NiDAB and the nervous tissue and the minimal immunohistochemical background, suppression of tissue argyrophilia with thioglycolic acid was unnecessary and omitted from the protocol. Subsequently, the sections were incubated in goat anti-ChAT (1:1500; catalog \#AB144P-1ML, Millipore; RRID:AB_262156), which was detected with biotinylated donkey anti-goat IgG (dilution, 1:500; overnight; Jackson ImmunoResearch), and $\mathrm{ABC}$ Elite solution (dilution, 1:500; $1.5 \mathrm{~h}$ ), pro- 
viding that the metallic shield (i.e., SGI-NiDAB) formed around the antigen-antibody complex prevents unwanted binding of Igs used for the detection of the second tissue antigen (Liposits et al., 1986). The ChAT-IR sites were visualized with DAB.

Immunofluorescent detection and $3 D$ reconstruction of GLYT1- and GLYT2-IR profiles. Sections containing the BF of ChAT ${ }^{\mathrm{BAC}}$-eGFP mice were incubated in a mixture of goat anti-GLYT1 (1: 10,000; catalog \#AB1770, Millipore; RRID:AB_90893) and rabbit anti-GLYT2 (N30aa; $1 \mu \mathrm{g} / \mathrm{ml}$ ) primary antibodies (for $48 \mathrm{~h}$ ). Then they were sequentially incubated in biotinylated donkey anti-goat IgG (dilution, 1:500; $2 \mathrm{~h}$; catalog \#705-065-147, Jackson ImmunoResearch), Vectastain ABC Elite solution (dilution, $1: 1000 ; 1 \mathrm{~h}$ ), biotinylated tyramide with $\mathrm{H}_{2} \mathrm{O}_{2}$ (dilution, 1:1000 and $0.006 \%$, respectively; $0.5 \mathrm{~h}$ ). Finally, the GLYT1-linked labeling complexes and the GLYT2-anti-GLYT2 complexes were visualized, respectively, with Alexa Fluor 594-Streptavidin (dilution, 1:500; $12 \mathrm{~h}$; S-11227, Invitrogen) and CY5-conjugated donkey anti-rabbit IgG (dilution, 1: 1000; overnight; catalog \#711-175-152, Jackson ImmunoResearch). The double-labeled sections (i.e., for GLYT1 and GLYT2) containing the eGFP-expressing ChAT neurons were imaged using a Nikon A1 Confocal Microscope. Multiple stacks of optical slices $(1024 \times 1024$ pixels; $z$-steps, $0.6 \mu \mathrm{m}$ ) were obtained by scanning selected areas with cholinergic neurons of the different subdivisions of BF using a $60 \times$ oilimmersion objective. To detect eGFP, Alexa Fluor 594, and CY5, laser lines of 488, 594, and $633 \mathrm{~nm}$, and dichroic/emission filters 560/500-530, $650 / 565-625$, and $660 \mathrm{~nm}$ long-pass filters were used, respectively. The emission images were recorded separately in green, red, and blue channels and were displayed with the ImageJ software. Appositions were identified at the orthogonal view of the confocal $z$-stacks, and the image was generated by reconstructing the labeled profiles in 3D using the Amira software (FEI Visualization Sciences Group).

Tissue preparation for electron microscopy. To investigate the morphological relationship of cholinergic neurons with plasma membrane glycine transporter-containing processes in the $\mathrm{BF}$ at the electron microscopic level, pre-embedding, double-label immunohistochemistry was performed. CD1 mice were deeply anesthetized and perfused transcardially, first with $10 \mathrm{ml}$ of $0.01 \mathrm{M}$ PBS, pH 7.4, followed by $30 \mathrm{ml}$ of $2 \%$ $\mathrm{PFA} / 4 \%$ acrolein in $0.1 \mathrm{M} \mathrm{PB}, \mathrm{pH} 7.4$, and then $10 \mathrm{ml}$ of $4 \%$ PFA in the same buffer. The brains were rapidly removed and fixed further in $4 \%$ PFA overnight at $4^{\circ} \mathrm{C}$ and then stored in PBS for $24 \mathrm{~h}$ at $4 \mathrm{C}^{\circ}$. Thirtymicrometer-thick coronal sections were cut with a vibratome and treated with $1 \%$ sodium borohydride $(30 \mathrm{~min})$ and $0.5 \% \mathrm{H}_{2} \mathrm{O}_{2}(15 \mathrm{~min})$ and permeabilized with three freeze-thaw cycles, as described previously (Jo et al., 2012).

Pre-embedding detection of GLYT1 or GLYT2 and ChAT-IRs. Sections of the BF were double labeled for ChAT and GLYT1- or GLYT2-IR, as described above for bright-field microscopy mapping. The doublelabeled sections were then treated with $1 \%$ osmium tetroxide $(1 \mathrm{~h})$ and $2 \%$ uranyl acetate (in 70\% ethanol; $40 \mathrm{~min}$ ), dehydrated in an ascending series of ethanol and propylene oxide, and flat embedded in TAAB 812 medium epoxy resin between glass microscope slides precoated with a liquid release agent (catalog \#70880, Electron Microscopy Sciences). The resin was allowed to polymerize at $56^{\circ} \mathrm{C}$ for $2 \mathrm{~d}$. The flat-embedded sections were initially investigated by light microscopy at $60 \times$ magnification; areas exhibiting appositions of GLYT1- or GLYT2-IR processes on the somatodendritic region of ChAT-IR neurons were selected for further processing. Semithin $(1 \mu \mathrm{m})$ and ultrathin $(50-60 \mathrm{~nm})$ sections were cut with a Leica Microsystems ultracut UCT ultramicrotome. The ultrathin sections were collected in ribbons onto Formvar-coated singleslot grids, contrasted with $2 \%$ lead citrate and examined with a Jeol $100 \mathrm{C}$ Transmission Electron Microscope.

Demonstration of glycine receptor-IR in cholinergic neurons. To detect glycine receptor (GlyR)-IR, sections of CD1 or ChAT-eGFP mice $(n=4)$ were subjected to pepsin $(1 \mathrm{mg} / \mathrm{ml}$ in $0.2 \mathrm{~N} \mathrm{HCl}$; DAKO) pretreatment for $2-3 \mathrm{~min}$ at $37^{\circ} \mathrm{C}$. After blocking nonspecific antibody binding with $2 \%$ NHS (20 min) sections were incubated $(72 \mathrm{~h})$ in a cocktail of the guinea pig anti-GlyR [1 $\mu \mathrm{g} / \mathrm{ml}$; \#105-136aa, a gift from Masahiko Watanabe, Hokkaido University (Hondo et al., 2011); RRID: AB_2571771] and goat anti-ChAT (1:1500; catalog \#AB144P-1ML, Millipore; RRID:AB_262156), or rabbit anti-GFP (1:2500; catalog
\#AB10145, Millipore; RRID:AB_1587096) primary antibodies. GlyR immunoreactivity was visualized with biotinylated donkey anti-guinea pig (1:1000; 2 h; catalog \#711-065-152, Jackson ImmunoResearch), Vectastain ABC Elite solution (1:1000; 1 h; PK-6100, Vector Laboratories), biotinylated tyramide with $\mathrm{H}_{2} \mathrm{O}_{2}(1: 1000$ and $0.006 \%$, respectively; $0.5 \mathrm{~h}$ ), and, finally, Alexa Fluor 594-streptavidin (1:500, 12 h; S-11227, Invitrogen). To visualize the cholinergic neurons, the sections were incubated in FITC-donkey anti-goat IgG (dilution, 1:1000; overnight; catalog \#711-095-152, Jackson ImmunoResearch). Full sets of sections (which means every fourth sections from each brain with $50 \mu \mathrm{m}$ gaps between consecutive sections) were processed for the detection of panGlyR $\alpha$ immunoreactivity in cholinergic neurons of the mouse BF. Each of the subdivisions was scanned in the confocal microscope, and 5-10 cells per regions were investigated for colocalization.

Tract tracing and mapping of retrogradely labeled neurons. To label glycinergic neurons projecting to forebrain, GLYT2-GFP mice $(n=12)$ were given cholera toxin B (CTB; $0.5 \%$ solution; catalog \#103, List Biological Laboratories) or Fluoro-Gold (2.5-5.0\% FG, diluted in distilled water; Fluorochrome; but see Schmued and Fallon, 1986) via unilateral iontophoresis ( $5 \mu \mathrm{A}, 7 \mathrm{~s}$ on-off) into the BF for $20 \mathrm{~min}$. For targeting different subdivisions, the following stereotaxic coordinates were used, respectively, with reference to the bregma (B) planes: MS: anteroposterior, $+0.61 \mathrm{~mm}$; mediolateral, $+0.0 \mathrm{~mm}$; dorsoventral, $-4 \mathrm{~mm}$; HDB: anteroposterior, +0.37 or $+0.02 \mathrm{~mm}$; mediolateral, +0.80 or +1.40 $\mathrm{mm}$; dorsoventral, -4.90 or $-5.00 \mathrm{~mm}$ (Paxinos, 2013); and VP/SI: anteroposterior, $+0.13 \mathrm{~mm}$; mediolateral, $+1.20 \mathrm{~mm}$; dorsoventral, $-4.25 \mathrm{~mm}$. After a $6-10$ day transport time, animals were deeply anesthetized and perfused first with $20 \mathrm{ml}$ of PBS, followed by $0.1 \mathrm{M}$ PBS containing 4\% PFA. The brains were removed, immersed in 30\% sucrose for 1-2 d, and frozen on dry ice, and $25-\mu \mathrm{m}$-thick coronal sections were cut from the blocks of the forebrain +1.3 and $-1.3 \mathrm{~mm}$ from bregma and the brainstem expanding between bregma -2.9 and $-8 \mathrm{~mm}$ on a freezing microtome. The sections were divided into four sequential pools ( $\sim 20-22$ sections of the forebrain and $45-50$ sections of the brainstem in each set with $75 \mu \mathrm{m}$ gaps between consecutive sections). The location of CTB injection sites and the distribution of CTB-containing glycinergic neurons in the brainstem were studied in double-immunolabeled sections. A set of sections from each brain was pretreated first with $0.5 \%$ $\mathrm{H}_{2} \mathrm{O}_{2}$ and $0.5 \%$ Triton X-100 in PBS for 15 min and then $2 \%$ NHS in PBS for $20 \mathrm{~min}$. They were then incubated in the goat anti-CTB antiserum (catalog \#703, List Biological; RRID:AB_2313637) at 1:2000 for $2 \mathrm{~d}$ at $4^{\circ} \mathrm{C}$. After washes in PBS, they were immersed in CY3-donkey anti-goat IgG (1: 2000; Jackson ImmunoResearch) and incubated for $2 \mathrm{~h}$ at room temperature. Sections containing labeled cells with Fluoro-Gold were mounted and coverslipped with Vectashield mounting medium (Vector Laboratories), as described before. For mapping, the glycinergic neurons retrogradely labeled from the different BF regions every fifth sections with $75 \mu \mathrm{m}$ gaps in between were processed, and the sections containing the anatomical region (e.g., five sections/brain for the raphe magnus; $n=$ 6) with double-labeled cells (GLYT2-GFP and CTB-IR) were selected and photographed in the confocal microscope. The border of the anatomical region was defined (based on the corresponding atlas image) and each single- or double-labeled cell was counted in the region of interest to avoid problems arising from a potential uneven distribution of retrogradelabeled cells. Perikarya with a clear sign of nuclear presence were considered during the quantification, and colocalization of the signals was determined manually by turning the color channels alternatively on and off.

Immunohistochemical controls. The specificities of the ChAT, GLYT1, GLYT2, and GlyR primary antisera have been reported previously; thus, controls included preabsorption of the ChAT antibody with the corresponding protein antigen (Motts et al., 2008), immunoblot confirmation of GLYT2 and GlyR bands at the expected molecular weight in samples of transfected cells and mouse brain tissue (Hondo et al., 2011), and detection of GLYT1 mRNA signal in brain sections in comparative distribution to GLYT1 immunoreactivity (Kalló et al., 2008).

In the current study, the ChAT and GLYT2 antibody labeling did not reveal structures other than those detected by transgenic eGFP fluorescence expressed under the promoter of ChAT or GLYT2. The specific 
binding of the pan-GlyR $\alpha$ antibody to the glycine receptors was confirmed by a second $\alpha 2$ subunit-specific antiserum (catalog \#sc-17279, Santa Cruz Biotechnology; RRID:AB_2110230) detected in the same distribution in the BF. Increasing dilutions of the primary antisera resulted in a commensurate decrease and eventual disappearance of the immunostaining; omission of the primary antibodies or their preabsorption with corresponding peptide antigens resulted in a complete loss of the immunostaining. The secondary antibodies used here were designed for multiple labeling and were preabsorbed by the manufacturer with Igs from several species, including the one in which the other primary antibody had been raised.

\section{In vitro electrophysiology}

Animals, slice preparation, and chemicals. Mice expressing tdTomato fluorescent proteins in a ChAT-dependent way $(n=26)$ were used from both sexes. After decapitation of the animal and removal of the brain, $200-\mu \mathrm{m}$-thick coronal forebrain slices were prepared using a Microm HM 650 V Vibratome (Microm International) in ice-cold low-Na artificial CSF (aCSF) with the following ingredients (in mM): sucrose 130, glycerol 60, $\mathrm{NaCl} 25, \mathrm{KCl} 2.5, \mathrm{NaHCO}_{3} 26$, glucose $10, \mathrm{NaH}_{2} \mathrm{PO}_{4} 1.25$, $\mathrm{CaCl}_{2} 2, \mathrm{MgCl}_{2} 1$, myo-inositol 3, ascorbic acid 0.5 , and sodiumpyruvate $2, \mathrm{pH} 7.2$. After cutting, slices were incubated in normal aCSF for $60 \mathrm{~min}$ on $37^{\circ} \mathrm{C}$. The concentration of $\mathrm{NaCl}$ was elevated in normal aCSF to $120 \mathrm{~mm}$, while sucrose and glycerol were omitted from the solution. All chemicals were purchased from Sigma-Aldrich, unless stated otherwise. Brain slices were visualized with an Axioskop Microscope (Carl Zeiss). The microscope was equipped with a fluorescent imaging system (Till Photonics) containing a xenon bulb-based Polychrome V light source, a CCD camera (SensiCam, PCO AG) an imaging control unit, and the TillVISion software (version 4.0.1.3; T.I.L.L. Photonics). Patch pipettes with $5 \mathrm{M} \Omega$ pipette resistance were fabricated and filled with a solution containing the following (in $\mathrm{mM}$ ): $\mathrm{KCl} \mathrm{120,} \mathrm{NaCl} 5$, HEPES 10, EGTA 2, $\mathrm{CaCl}_{2}$ 0.1, Mg-ATP 5, $\mathrm{Na}_{3}$-GTP 0.3, $\mathrm{Na}_{2}$-phosphocreatinine 10 , and biocytin $8, \mathrm{pH} 7.3$. In a set of experiments, $\mathrm{KCl}$ was replaced with equimolar K-gluconate. To detect postsynaptic currents, whole-cell patch-clamp recordings were performed using an Axopatch 200A Amplifier (Molecular Devices) in voltage-clamp configuration at holding potentials $-120,-100,-60,-40$, and $0 \mathrm{mV}$. Action potential firing pattern was recorded in current-clamp configuration; the resting membrane potential was set to $-75 \mathrm{mV}$, and current injections were used from -30 to $+120 \mathrm{pA}$ in $10 \mathrm{pA}$ steps. All recordings were performed in normal aCSF at room temperature. Data acquisition was achieved using the Clampex 10.0 software (Molecular Devices), while data analysis was performed using Clampfit version 10.0 (Molecular Devices) and Mini Analysis (Synaptosoft) programs. When the latter software was used for event detection, traces, where all events were pharmacologically inhibited, were used for setting detection parameters; from cell to cell, the detection threshold of the events varied from 7 to $15 \mathrm{pA}(12.3 \pm 0.5 \mathrm{pA})$. Other parameters were set as follows: period to search a local maximum, $80 \mathrm{~ms}$; time before a peak for baseline, $20 \mathrm{~ms}$; area threshold, $5 \mathrm{fC}$; period to search a decay time, $40 \mathrm{~ms}$; and period to average a baseline, $1 \mathrm{~ms}$.

Pharmacology and visualization of the labeled neurons. When recording glycinergic IPSCs, slices were continuously perfused with $10 \mu \mathrm{M} 2,3-$ dihydroxy-6-nitro-7-sulfonyl-benzo[f] quinoxaline (NBQX), $50 \mu \mathrm{M}$ $\mathrm{D}(-)$-2-amino-5-phosphonopentanoic acid (D-AP5; Tocris Cookson), and $10 \mu \mathrm{M}$ bicuculline to block ionotropic glutamatergic and GABAergic neurotransmissions (GG Blocking Cocktail). This cocktail was later completed with $1 \mu \mathrm{M}$ strychnine to show that the observed IPSCs are strychnine sensitive. The neurons were filled with biocytin during the electrophysiological recordings. The slices accommodating the filled neurons were fixed overnight (4\% PFA in $0.1 \mathrm{~m}$ phosphate buffer; $\mathrm{pH}$ 7.4; $4^{\circ} \mathrm{C}$ ). Permeabilization was achieved in Tris-buffered saline (in mM: Tris base 8 , Trisma $\mathrm{HCl} 42$, and $\mathrm{NaCl} 150, \mathrm{pH}$ 7.4) supplemented with $0.1 \%$ Triton X-100 and $10 \%$ bovine serum ( $60 \mathrm{~min})$. The slices were incubated in phosphate buffer containing streptavidin-conjugated Alexa Fluor 488 (1:300; Invitrogen) for $90 \mathrm{~min}$. The cells were visualized using a Zeiss LSM 510 confocal microscope (Carl Zeiss AG).

\section{Experimental design and statistical analysis}

Anatomical studies. Wild-type $(n=21)$ and transgenic male mice

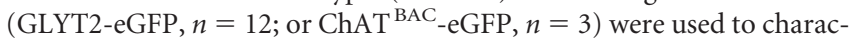
terize the cellular interaction in the $\mathrm{BF}$ potentially providing glycinergic input to cholinergic neurons. Efforts were made to keep animal usage at a minimum while ensuring representation of the different subdivisions of the $\mathrm{BF}$ in the analysis of morphological interactions of receptors or inputs on cholinergic neurons. Every fourth (with $50 \mu \mathrm{m}$ tissue gaps) section was processed from each brain for a certain type of immunostaining, and for each of the BF subdivisions confocal microscopy was used to scan 5-10 cholinergic cells for colocalization of receptor on cholinergic neurons. To better define anatomical regions, immunostained sections were compared with their matching counterstained pairs. For synaptic interactions of glycine axons, 32 synapses were identified with cholinergic profiles from randomly selected close appositions $(n=84)$. For assessing the importance of brainstem sites projecting to the cholinergic forebrain, each single- and double-labeled neuron was counted in sets of 1:5 series, with $75 \mu \mathrm{m}$ gaps between consecutive sections. A set of sections from brains with different BF injection sites (see Fig. 7) of the retrograde tracer were analyzed. The percentages of the retrogradely labeled glycinergic neurons in the nucleus raphe magnus of six animals were averaged from counts of 30 sections (5 sections/brain). Immunohistochemical controls involved tests to exclude false negativity and positivity potentially generated either by the animal models, reagents, or methods used (see Immunohistochemical controls for details).

In vitro electrophysiology. ChAT-tdTomato mice $(n=26)$ were used from both sexes. Slices were cut from the basal forebrain region and used to record from cholinergic neurons $(n=46)$ of the different subdivisions of the basal forebrain. One neuron was patched in each slice. All data represent the mean \pm SEM. Postsynaptic currents detected by whole-cell patch-clamp recordings in voltage-clamp configuration were characterized for amplitude and frequency under control conditions and pharmacological interventions. To distinguish early-firing (EF) and late-firing (LF) cholinergic neurons, the action potential firing pattern was recorded in current-clamp configuration. Statistical significance was determined using Student's $t$ test. Two-sample Kolmogorov-Smirnov test was used for comparison of amplitude, rise time, and decay time of IPSCs in different neuronal populations. The level of significance was $p<0.05$.

\section{Results}

\section{Cholinergic neurons are immunoreactive for} glycine receptors

Using a pan-GlyR $\alpha$ antibody, immunoreactive puncta were detected in all subdivisions of BF. The ventral pallidum showed the weakest pan-GlyR $\alpha$ immunoreactivity; no obvious difference could be observed in the intensity of staining in the MS, VDB/ HDB, SI, and basal nucleus Meynert. The deposited immunohistochemical reaction product often delineated cellular borders even in weakly labeled areas (Fig. $1 A-C$ ). Confocal microscopic analyses of double-labeled sections identified GlyR-IR sites at the periphery of most cholinergic neurons (Fig. $1 D-E$ ), indicating that glycine can directly influence BF cholinergic functions.

\section{Cholinergic neurons exhibit strychnine-sensitive IPSCs}

Whole-cell patch-clamp recordings were performed on 36 genetically identified cholinergic neurons from the medial septal nucleus, the horizontal diagonal band, the ventral pallidum, the substantia innominate, and the lateral nucleus of the diagonal band (LDB). To increase the amplitude of chloride currents, a $\mathrm{KCl}$-based internal solution was applied in the recording pipettes. Thirty-one of the neurons displayed bicuculline-resistant, strychnine-sensitive spontaneous IPSCs with an average frequency of $0.81 \pm 0.25 \times 10^{-1} \mathrm{~Hz}$ (range, $0.04-9.22 \times 10^{-1} \mathrm{~Hz}$; $t_{(36)}=4.68, p=0.0008$, paired $t$ test, compared with control) and an average amplitude of $15.23 \pm 1.38 \mathrm{pA}$ (range, 8.4-29.9 pA; $t_{(39)}=5.28, p=0.0009$, paired $t$ test, compared with control; Fig. 

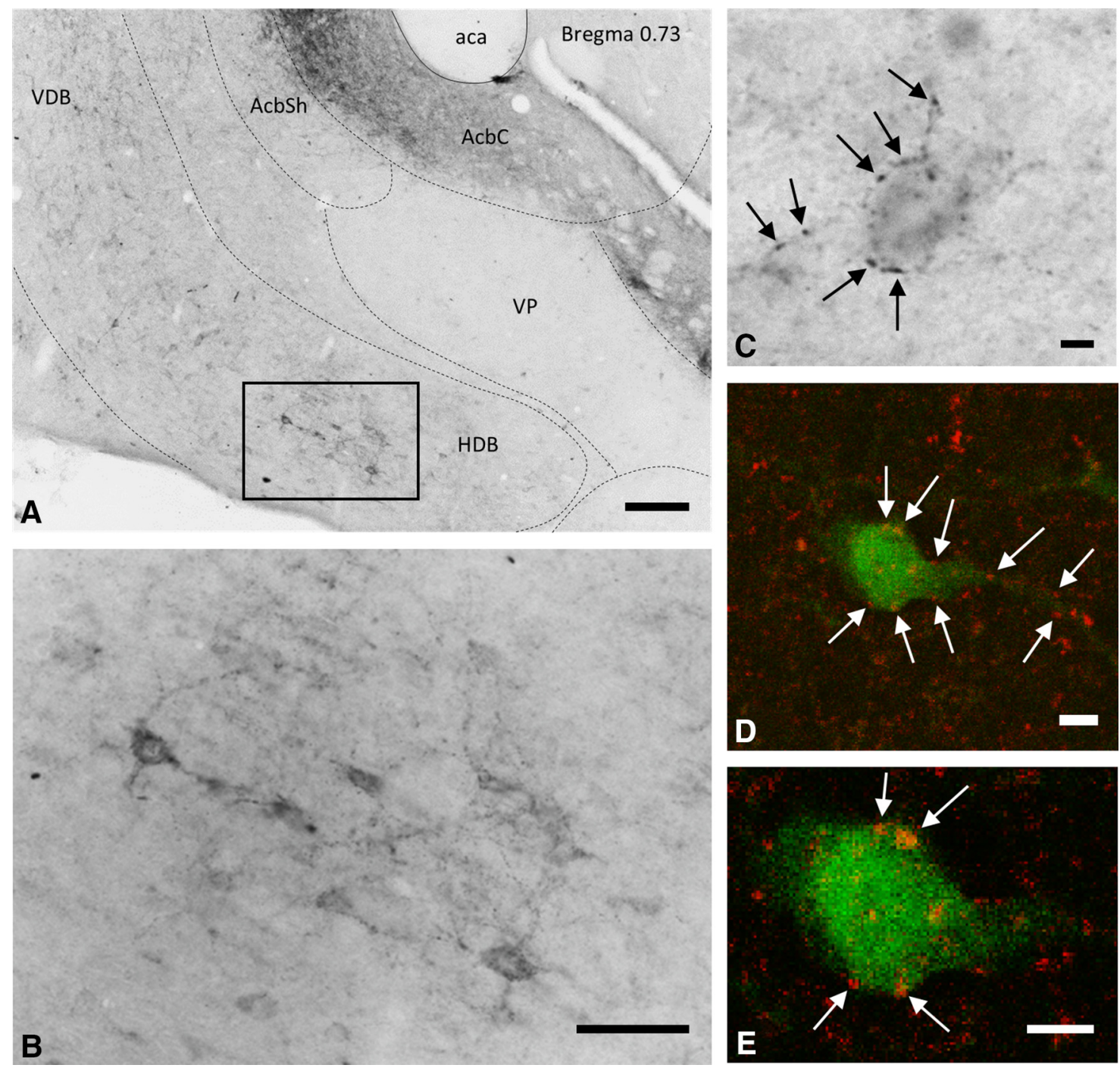

Figure 1. Distribution of GlyR-IR sites in the basal forebrain detected by a pan-GlyR $\alpha$ antibody. $A$, The punctate appearance of GlyR-immunoreactivity (revealed by NiDAB) often delineates cellular borders in the strongly labeled accumbens core, in the medium labeled HDB, as well as in the weakly labeled ventral pallidum (bregma level, 0.73 ). The boxed area of $H D B$ is further magnified in $\boldsymbol{B}$ showing GlyR immunoreactivity in the perikaryon as well as in the processes of cells. $\boldsymbol{C}$, A high-power photograph of a single cell, with GlyR-IR sites primarily distributed at the periphery of the cell (arrows). D, E, Confocal microscopic images of two optical slices $(0.75 \mu \mathrm{m})$ of a ChAT-eGFP neuron exhibiting GlyR-IR sites at the contour of the cell (arrows). aca, Anterior commissure, anterior part; $A c b C$, accumbens nucleus, core region; $A c b S h$, accumbens nucleus, shell region. Scale bars: $A, B, 100 \mu \mathrm{m} ; \boldsymbol{C}, 10 \mu \mathrm{m} ; \boldsymbol{D}, \boldsymbol{E}, 5 \mu \mathrm{m}$. Contrast and brightness were adjusted by the Curves function of Adobe Photoshop 5.1.

$2 A-D)$. A mean of $11.2 \pm 2.7 \%$ of all synaptic events remained detectable after application of the GG blocking cocktail, but were completely eliminated by strychnine added into the incubating medium (for frequency: $t_{(23)}=3.39, p=0.001$; for amplitude: $t_{(23)}=18.47, p=1.35823 \times 10^{-15}$, paired $t$ test). The number of putative glycinergic IPSCs analyzed per cells varied from 6 to 153 events during the recording periods. However, the distribution of the IPSC frequency was not uniform: among the recorded cells, there was a slight ventrolateral-dorsomedial gradient of IPSC frequency (Fig. 2E).

To ensure that the strychnine-sensitive events were chloride currents, the reversal potential had also be examined. First, recordings were performed by using $\mathrm{KCl}$-filled pipettes at holding potentials of -60 and $-100 \mathrm{mV}$. To avoid bias in determining the average amplitude of events by involving low-amplitude events appearing at $-100 \mathrm{mV}$ due to higher driving force for chloride, the amplitudes of the three largest events were considered from each recording; their average values were plotted against the holding potentials. Recordings were also made on -40 and $0 \mathrm{mV}$ holding potentials, but no events could be detected, very likely because amplitude of events at this range of holding potentials fell under the detection threshold. Reversal potential was determined by the intersection of the linear fit of the averaged data with the abscissa of membrane potentials. The extrapolated value $(+5.5$ $\mathrm{mV} ; n=8)$ was close to the calculated equilibrium potential of chloride ( $-0.6 \mathrm{mV}$; Fig. $2 G$ ). Based on these reversal potential values, it is very likely that the recorded bicuculline-resistant events were not based on potassium currents, as the calculated reversal potential for potassium would be $-99.1 \mathrm{mV}$ in these conditions. Of note, mixed cationic conductances (Kandel et al., 2013) could have still served as a background of the observed events. To exclude this possibility, $\mathrm{KCl}$ was replaced with K-gluconate in the internal solution of the recording pipette $(n=10)$, resulting in a calculated equilibrium potential for chloride at $-83.1 \mathrm{mV}$. Contrasting the traces recorded with $\mathrm{KCl}$-containing pipettes that show negative-going events at $-60 \mathrm{mV}$ holding po- 
A

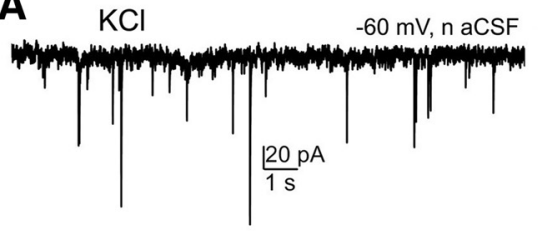

B

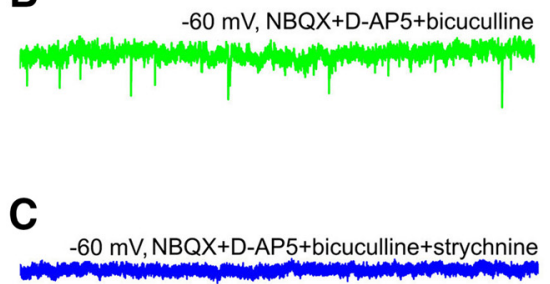

D
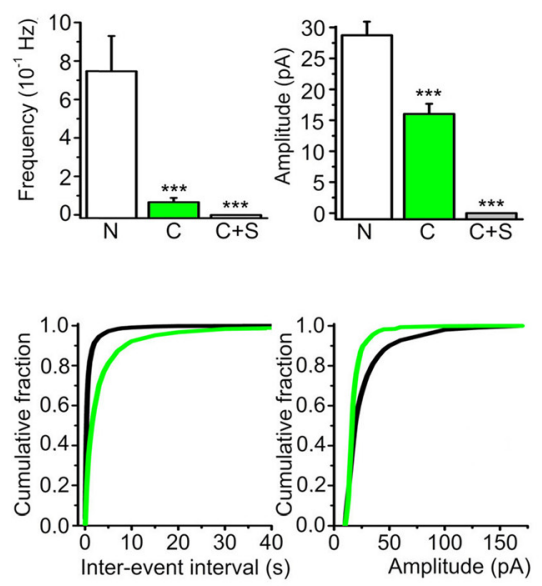

H
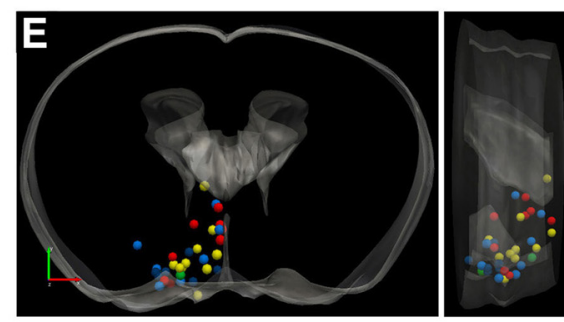

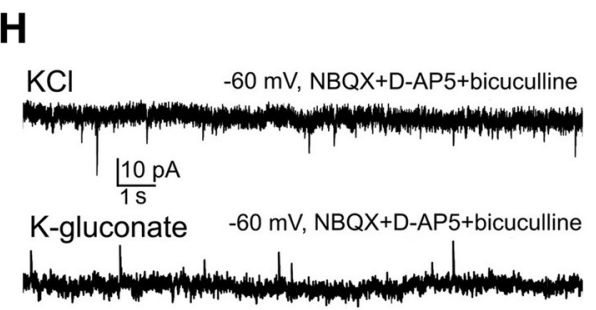

G

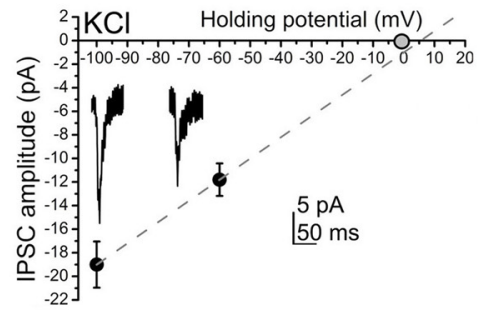

I

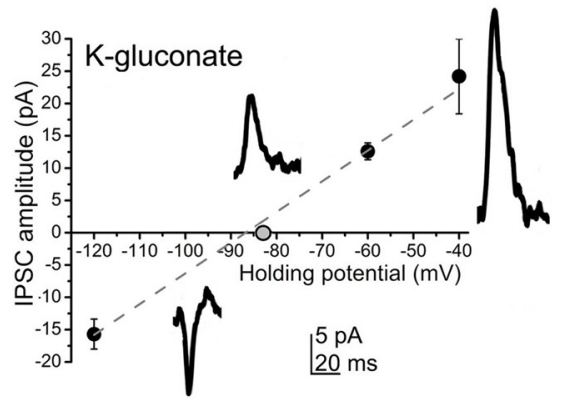

Figure 2. Glycinergic IPSCS recorded on cholinergic neurons in the basal forebrain. $A, A$ 10-s-long representative trace of spontaneous (excitatory and inhibitory) postsynaptic currents recorded in normal aCSF. $\boldsymbol{B}$, Inhibitors of ionotropic glutamate receptors (NBQX, D-AP5) and GABA receptors (bicuculline) did not fully abolish postsynaptic currents. $C$, Adding strychnine to the recording cocktail blocked all events. $D$, Bar chart diagrams of the frequency and amplitude of the recorded events (average $\pm S E M)$ in normal aCSF (N, hollow), with NBQX, D-AP5, and bicuculline (C; green) and with additional strychnine application ( $C+S$; gray). All differences were statistically significant $(p<0.001)$. Cumulative histogram of the interevent interval and amplitude of synaptic events in normal aCSF (black) or in the presence of the NBQX-, D-AP5-, and bicuculline-containing blocking cocktail (green). All differences were statistically significant (Kolmogorov-Smirnov test; $p<$ 0.001). $\boldsymbol{E}$, Positions of the recorded neuronal somata in the basal forebrain shown by dots. Differences in the frequency of the strychnine-sensitive events are color coded. The mouse forebrain is reconstructed, and the distribution of recorded cells is shown from two different angles (axial and lateral views; based on the mouse brain atlas (Paxinos, 2013). $\boldsymbol{F}$, Confocal image of a biocytin-filled cholinergic neuron from the HDB. The inserts are magnified images of the boxed areas and show secondary dendritic processes with scattered spines (arrows and asterisks). $\mathbf{G}$, Determination of the reversal potential of the strychnine-sensitive events with $\mathrm{KCl}$-based pipette solution $\left(\mathrm{E}_{\mathrm{Cl}}^{-}=-0.6 \mathrm{mV}\right)$. Black dots, Average $\pm \mathrm{SEM}$ of the three largest events of each trace; dashed line, linear fit of the average values; gray dot, calculated equilibrium potential of chloride. Representative current traces belonging to different holding potentials are also included in the inserts. $\boldsymbol{H}$, Current traces recorded with $\mathrm{KCl}^{-}\left(\mathrm{E}_{\mathrm{Cl}}^{-}=-0.6 \mathrm{mV}\right)$ and K-gluconate-based $\left(\mathrm{E}_{\mathrm{Cl}}^{-}=-83.1 \mathrm{mV}\right)$ pipette solutions. I, Determination of the reversal potential of the strychnine-sensitive events with $\mathrm{K}$-gluconatebased pipette solution ( $\mathrm{E}_{\mathrm{Cl}}^{-}=-83.1 \mathrm{mV}$ ). Black dots, Average $\pm \mathrm{SEM}$ of the three largest events of each trace; gray line, linear fit of the average values; gray dot, calculated equilibrium potential of chloride. Current traces recorded with K-gluconate-based $\left(\mathrm{E}_{\mathrm{Cl}}^{-}=-83.1 \mathrm{mV}\right)$ pipette solutions at different holding potentials $(-120,-60$, and $-40 \mathrm{mV} ; n=7)$ are also shown in the inserts. Scale bars: $E, 1 \mathrm{~mm} ; \boldsymbol{F}, 20 \mu \mathrm{m}$; small insert, $10 \mu \mathrm{m}$.

tential in the presence of the GG blocking cocktail (Fig. 2B), negative-going events were almost completely absent $(0.01 \pm$ $0.007 \times 10^{-1} \mathrm{~Hz}$ ) when K-gluconate-filled pipettes were used (Fig. 2H). Application of the GG blocking cocktail significantly reduced the appearance of such events $\left(_{(6)}=2.97, p=0.01\right.$, paired $t$ test; from $1.41 \pm 0.47 \times 10^{-1} \mathrm{~Hz}$ seen in control conditions). In turn, bicuculline-resistant, positive-going events were seen in seven cases with an average amplitude of $12.6 \pm 1.1 \mathrm{pA}$ (Fig. $2 \mathrm{H}$ ). The frequency of these positive-going events ( $0.47 \pm$ $0.13 \times 10^{-1} \mathrm{~Hz}$ ) and the negative-going events recorded with the $\mathrm{KCl}$-containing pipettes were not significantly different $\left(t_{(29)}=\right.$ $0.74, p=0.25$, two-sample $t$ test). These experiments support the hypothesis that the strychnine-sensitive events recorded were truly chloride currents. By using the K-gluconate-filled pipettes, bicuculline-resistant events were recorded at $-120,-60$, and $-40 \mathrm{mV}$ holding potentials $(n=5)$, and the average amplitudes were plotted against the holding potentials, as described above. The linear fit crossed the abscissa at $-86.9 \mathrm{mV}$, which is close to the reversal potential of chloride calculated with the Nernst equa- tion $(-83.1 \mathrm{mV})$; thus, mixed cationic currents as background of these events were clearly excluded (Fig. 2I).

The firing pattern of the neurons was also recorded in 28 cases, using current-clamp mode and depolarizing current injections in $10 \mathrm{pA}$ steps, and the action potential firing pattern was evaluated at the step using $60 \mathrm{pA}$ current injection. Twenty-two of the neurons proved to be $\mathrm{EF}$ (Fig. $3 A, C$ ), and the other 6 were LF (Fig. 3 B, C). In accordance with the findings of Unal et al. (2012), these neurons possessed similar input resistance values (606.6 \pm $89 \mathrm{M} \Omega$ for the EF and $628.3 \pm 79 \mathrm{M} \Omega$ for the LF; $t_{(12)}=0.174$, $p=0.43$, two-sample $t$ test) but showed significant differences in the delay of the first action potential $(43.4 \pm 5.4 \mathrm{~ms}$ for EF and $247.9 \pm 19.8 \mathrm{~ms} \mathrm{LF} ; t_{(16)}=10.06, p=1.26 \times 10^{-8}$, two-sample $t$ test). When the glycinergic sIPSCs ( sIPSC $_{\mathrm{G}} \mathrm{s}$ ) were compared in $\mathrm{EF}$ and LF neurons, significantly longer interevent intervals were seen in LF neurons ( $p=0.018$; Kolmogorov-Smirnov test). In contrast, EF neurons $(n=20)$ showed sIPSC $_{\mathrm{G}} \mathrm{S}$ with significantly higher amplitude $\left(p=3.15 \times 10^{-7}\right)$, shorter rise time $(p=$ $0.008)$ and longer decay time $\left(p=2.19 \times 10^{-4}\right)$ than LF cholin- 
A

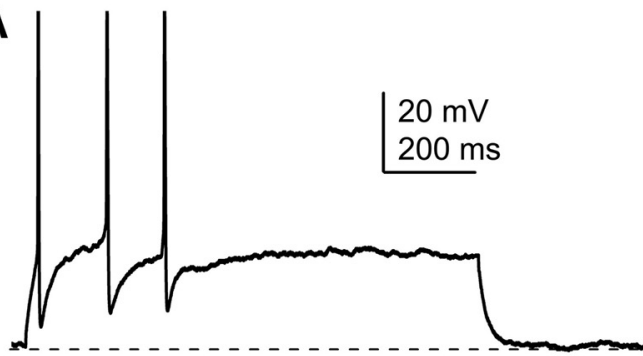

B

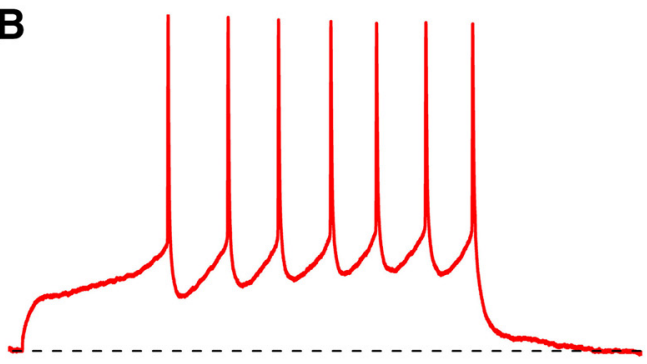

D

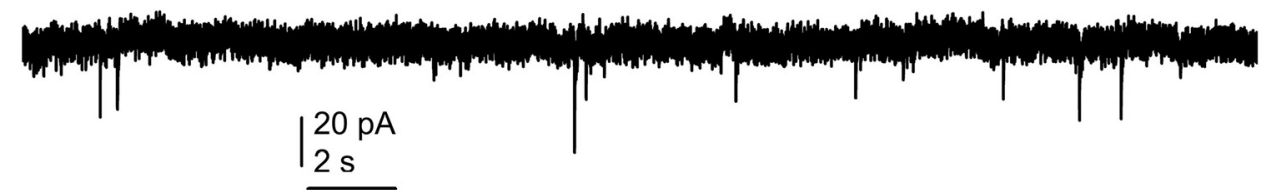

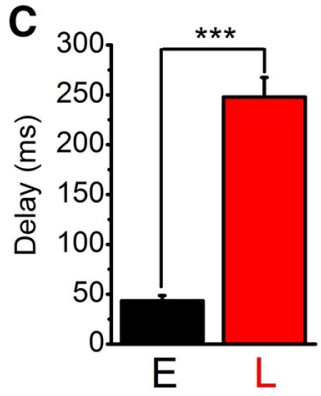

E

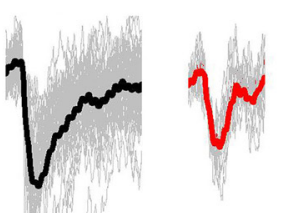

$10 \mathrm{pA}$ $50 \mathrm{~ms}$

$\mathbf{F}$
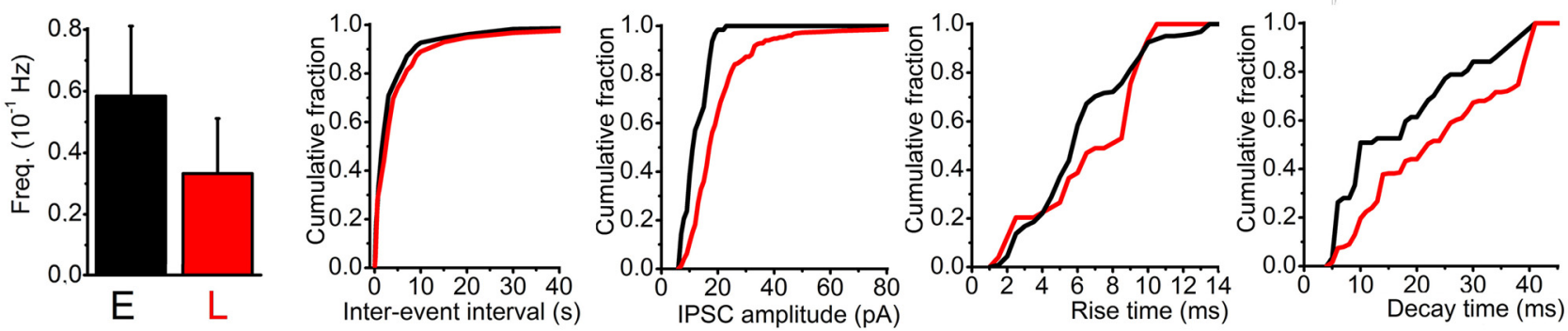

Figure 3. Differences between the glycinergic sIPSCs recorded from early- and late-firing BF cholinergic neurons. $A$, Firing pattern of an early-firing neuron elicited by a $60 \mathrm{pA}$ depolarizing current injection. $\boldsymbol{B}$, Firing pattern of a late-firing neuron, elicited by $60 \mathrm{pA}$ depolarizing current injection. The dashed line indicates $-75 \mathrm{mV}$. C, Statistical summary of the delay (time between the beginning of the rheobase current injection and the first action potential, from $-75 \mathrm{mV}$ holding potential) of early-firing (E, black) and late-firing $(\mathrm{L}$, red) neurons $(* * * p<0.001)$. $\boldsymbol{D}$, Representative trace of glycinergic events from an early-firing neuron (black trace) and a late firing neuron (red trace). $\boldsymbol{E}$, Glycinergic IPSCs from an early-firing (left) and a late-firing (right) cholinergic BF neuron. Gray traces, individual IPSCs; black trace, average of spontaneous glycinergic IPSCs from an early firing neuron; red trace, average of spontaneous glycinergic IPSCs from a late firing neuron. $\boldsymbol{F}$, Statistical summary of the observed differences between early-firing (black) and late-firing (red) neurons with bar charts [black, early firing (E); red, late firing (L); average \pm SEM] and cumulative histograms. Interevent interval, time between two glycinergic IPSCs in seconds; amplitude differences of the glycinergic events in pA; rise, rise time; decay, decay time in milliseconds.

ergic neurons $(n=6$; Kolmogorov-Smirnov test; two of the early firing neurons did not show IPSC $_{\mathrm{G}} \mathrm{s}$ and were excluded from evaluation of these parameters; Fig. $3 D-F$ ). When neurons lacking IIPSC $_{G}$ s were included in the statistical analysis, due to the variability of sIPSC $_{\mathrm{G}}$ frequency, no significant difference was revealed between EF and LF neurons in this parameter $(0.33 \pm$ $0.18 \times 10^{-1} \mathrm{~Hz}$ for EF neurons and $0.5 \pm 0.16 \times 10^{-1} \mathrm{~Hz}$ for $\mathrm{LF}$ neurons).

\section{Distribution of glycinergic (GLYT2-IR) axons in the BF}

Although the location of glycinergic cell bodies is mainly restricted to the spinal cord and the brainstem, the axonal projections from the brainstem reach most of the forebrain regions, including the BF. By immunohistochemically labeling GLYT2, the plasma membrane transporter of glycine, we detected a high density of glycinergic axons in the mouse BF, including the areas where ChAT-IR neurons are clustered [i.e., GLYT2-IR fibers were observed in the MS, VDB, HDB, LDB, VP, SI, and the extension of the amygdala (EA); Fig. 4A-E]. Bright-field (Figs. $4 F$, $5 A-C$ ) and electron microscopic approaches (Fig. 5D-G) revealed axosomatic and axodendritic connections between GLYT2-positive axon terminals and ChAT-IR neurons. Analyses of high-power images often revealed GLYT2-IR fiber varicosities, with a central nonlabeled area indicating embedded processes of target cells and concave joined surfaces (Fig. $5 B, C$, insets). At the ultrastructural level, 32 synapses were identified with cholinergic profiles; GLYT2-IR axon terminals were found to surround smaller-diameter as well as larger-diameter ChAT-IR dendrites (Fig. $5 E, F$ ) and formed symmetric synapses with dendritic shafts (Fig. 5D-F; $n=20$ ) and perikarya (Fig. $5 G ; n=1$ ). In addition, the correlated bright-field (Fig. 6A) and electron microscopic (Fig. $6 B-D$ ) approach and analysis of serial ultrathin sections also revealed axospinous connections on somatic spines (Fig. 6C; $n=2$ ) and dendritic spines (Fig. $6 D ; n=9$ ).

\section{Brainstem nuclei provide the $\mathrm{BF}$ with glycinergic input}

To identify the source of glycinergic input to the BF, the retrograde tracers CTB or Fluoro-Gold were injected into the MS, HDB, VP, and SI (Fig. 7A-D) of mice expressing GFP under the control of GLYT2 promoter. Although the distribution of retrogradely labeled GFP-positive neurons varied from brain to brain depending on the exact locations and sizes of injection sites, there were brainstem areas and nuclei commonly labeled for the tracer (Fig. 7E). The highest number of double-labeled neurons were in 

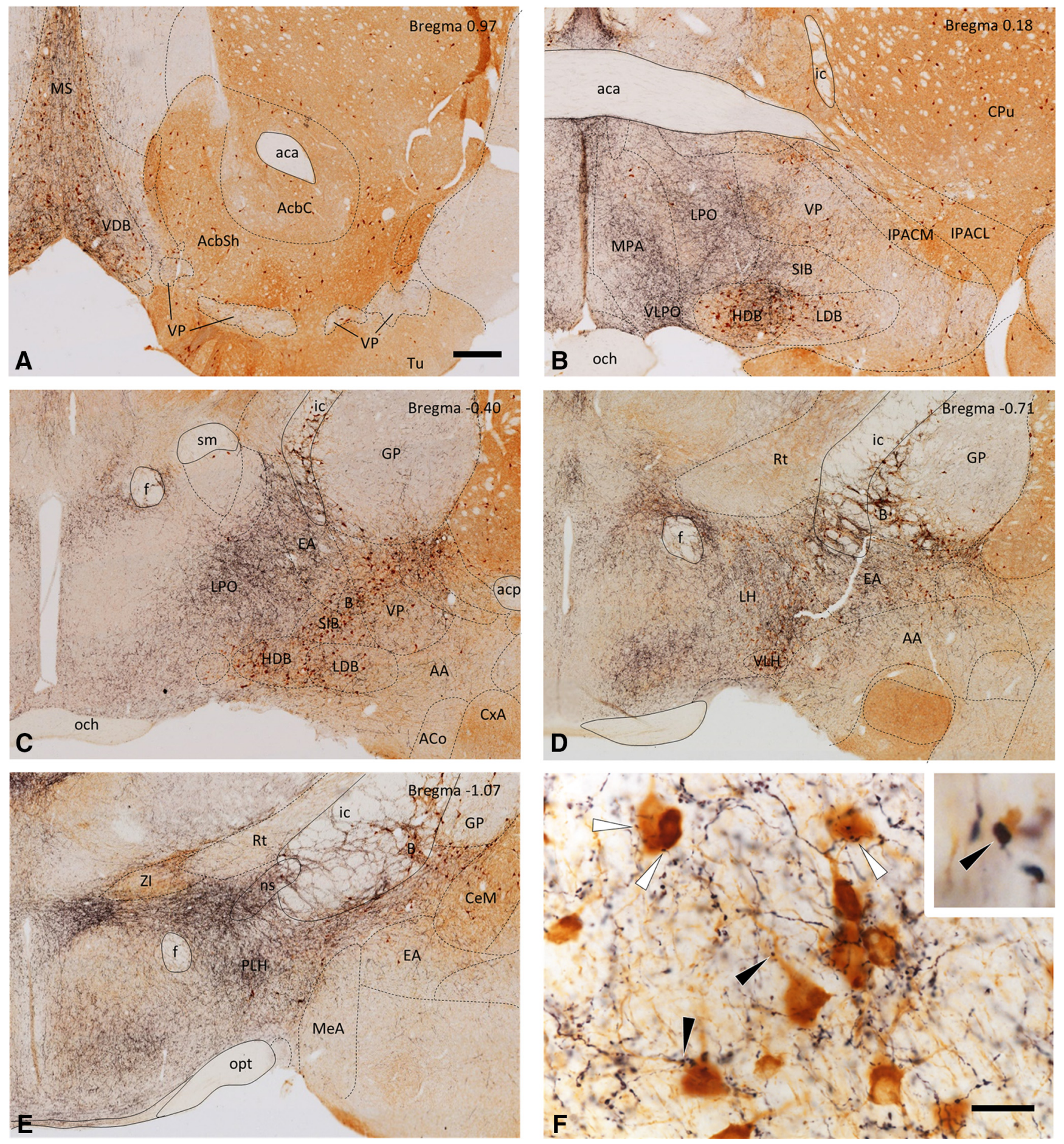

Figure 4. $\quad A-E$, Dual immunohistochemical labeling to identify the relationship between GLYT2-IR fibers and ChAT-IR neurons in the basal forebrain. Distribution of GLYT2/ChAT-IR cellular profiles in the basal forebrain shown in coronal sections at five different rostrocaudal levels. Rich network of GLYT2-immunoreactive fibers is present in regions of the basal forebrain where cholinergic neurons are located [i.e., MS (Ch1), VDB (Ch2), HDB (Ch3), VP (Ch4), and SI (Ch4); Mesulam et al., 1983]. The rostrocaudal levels are given in millimeters from the bregma, based upon the mouse brain atlas (Paxinos, 2013). A medium power image shows GLYT2-IR fiber varicosities adjacent to ChAT-IR soma (white arrowheads) and dendrites (black arrowheads) in the HDB. The inset highlights one of these appositions. AA, Anterior amygdaloid area; ACo, anterior cortical amygdaloid nucleus; acp, anterior commissure, posterior limb; B, basal nucleus (Meynert); CeM, central amygdaloid nu, medial; (pu, caudate-putamen (striatum); $\mathrm{XAA}$, cortex-amygdala transition zone; f, fornix; GP, globus pallidus; ic, internal capsule; IPACL, interstitial nucleus of the posterior limb of the anterior commissure, lateral part; IPACM, interstitial nucleus of the posterior limb of the anterior commissure, medial part; LH, lateral hypothalamic area; LP0, lateral preoptic area; MeA, medial amygdaloid nucleus, anterior part; MPA, medial preoptic area; ns, nigrostriatal bundle; och, optic chiasm; opt, optic tract; PLH, peduncular lateral hypothal; Rt, reticular nucleus (prethalamus); SIB, SI, basal part; sm, stria medullaris; Tu, olfactory tubercle; VLH, ventrolateral hypothalamic nucleus; VLP0, ventrolateral preoptic nucleus; Zl, zona incerta. Scale bars: $A-E$, $500 \mu \mathrm{m}$; $\boldsymbol{F}, 25 \mu \mathrm{m}$. Contrast and brightness were adjusted using the Curves function of Adobe Photoshop 5.1. 

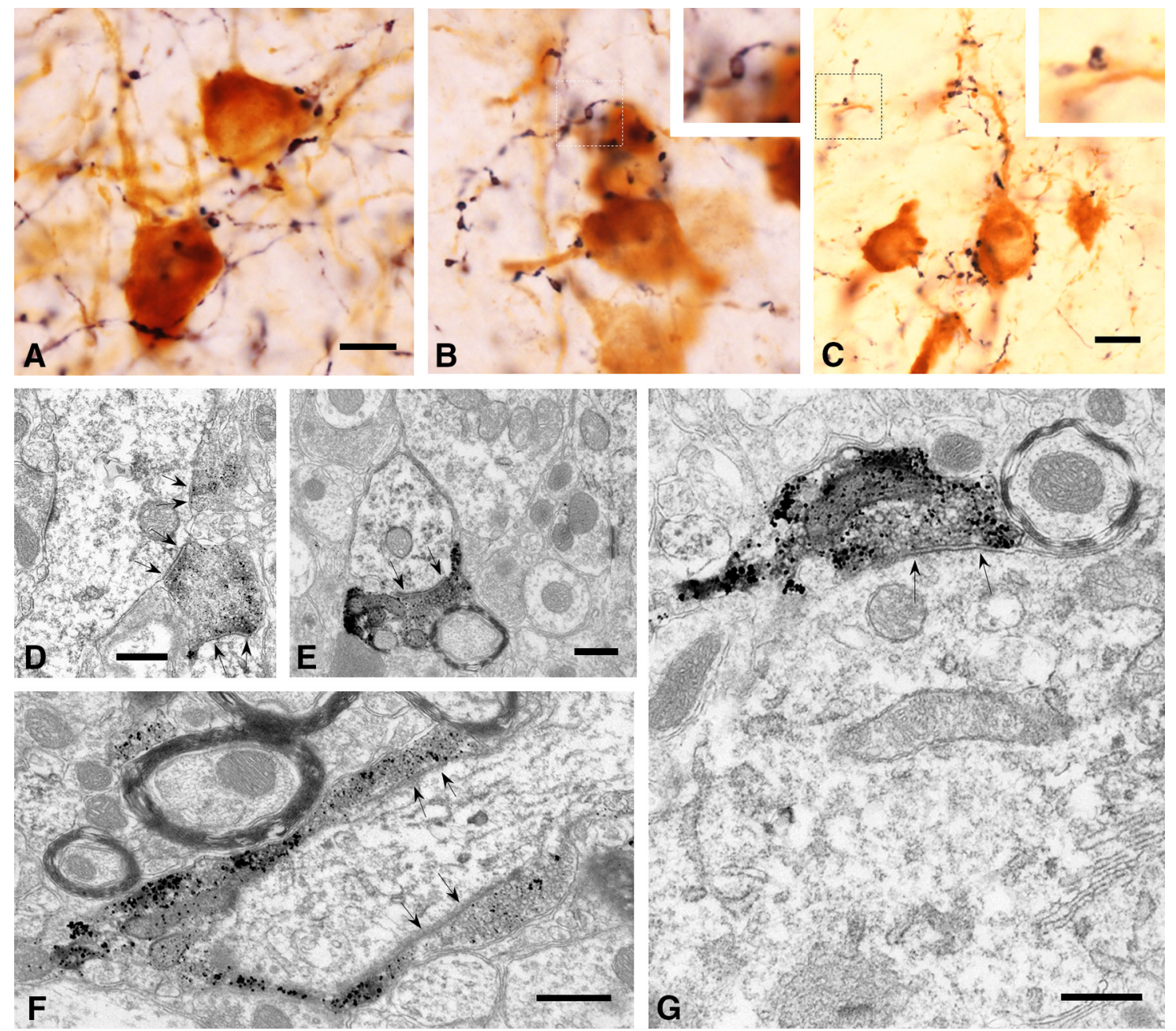

Figure 5. Bright-field and electron microscopic images of GLYT2-IR fibers in apposition to ChAT-IR neurons of the basal forebrain. A-C, Varicose GLYT2-IR axons establish axosomatic and axodendritic connections with ChAT-IR neurons in the medial septum $(\boldsymbol{A})$, the nucleus of the horizontal limb of the diagonal band $(\boldsymbol{B})$, and the basal nucleus $(\boldsymbol{C})$. The axon varicosities often surround or embed neural profiles, as demonstrated by the insets, showing central lighter areas in certain axon varicosities. $\boldsymbol{D}-\mathbf{G}$, The appositions between GLYT2-IR axons and ChAT-IR dendrites ( $\boldsymbol{D}-\boldsymbol{F}$ ) or soma (G) often proved to be synaptic connections (black arrows) showing characteristics of the symmetric types. Scale bars: $A-C, 10 \mu \mathrm{m} ; \mathbf{D}-\mathbf{G}, 500 \mathrm{~nm}$.

the raphe magnus (Fig. $7 E-I ; 25 \pm 7.4 \%$ of all GFP neurons, $n=6)$. Retrogradely labeled GFP-positive neurons were also commonly present in the different parts of the pontine reticular nucleus and the gigantocellular reticular nucleus. A few cells could also be detected in the periaqueductal gray (Fig. 7E).

\section{GLYT1 is also present in the BF}

In $\mathrm{BF}$ regions, immunoreactivity for GLYT1 was very strong (Fig. $8 A-F)$. Immunohistochemical colabeling with the astroglial marker glutamine synthetase revealed that GLYT1 is primarily present in astrocytes (data not shown). Confocal microscopic analysis detected GLYT1-IR thin astrocytic processes in the vicinity of axon varicosities in apposition to cholinergic neurons (Fig. $9 A-D)$ in all studied BF regions. At the ultrastructural level, the presence of GLYT1 immunoreactivity in thin glial processes was confirmed, often adjacent to axon terminals establishing asymmetric or symmetric synapse with the cholinergic neurons (Fig. $10 A-D)$.

\section{Discussion}

According to the classical concept of the ascending arousal system (Nauta and Kuypers, 1957), a major branch of the complex pathways from the rostral pons and caudal midbrain reaches the hypothalamus and the BF and mediates activating function for these brain regions. Subsequent studies identified inputs from the locus ceruleus; from the adrenergic, dopaminergic brainstem neurons; and from the parabrachial nucleus to synapse with the BF neurons, including cholinergic, glutamatergic, and parvalbumincontaining neurons using electron microscopy (Záborszky et al., 1993,1999; Gaykema and Zaborszky, 1997; Hajszán and Zaborszky, 2002) or viral tracing (Fuller et al., 2011; Kaur et al., 2013; Anaclet et al., 2014). The current morphological and functional analyses identified for the first time an ascending glycinergic pathway from the nucleus raphe magnus and neighboring reticular formation of the pons to the BF cholinergic neurons. Glycine exhibits bicuculline-resistant, strychnine-sensitive sIPSCs on BFC neurons.

\section{Glycine is a major transmitter in the $\mathrm{BF}$}

The current data support a substantial glycinergic input to cholinergic neurons in all subdivisions of the BF. Approximately $80 \%$ of the recorded neurons, selected randomly from the medial septal nucleus, the horizontal diagonal band, the ventral pallidum, substantia innominate, and the lateral nucleus of the diagonal band, displayed bicuculline-resistant, strychnine-sensitive spontaneous IPSCs. Based on the reversal potential calculations 

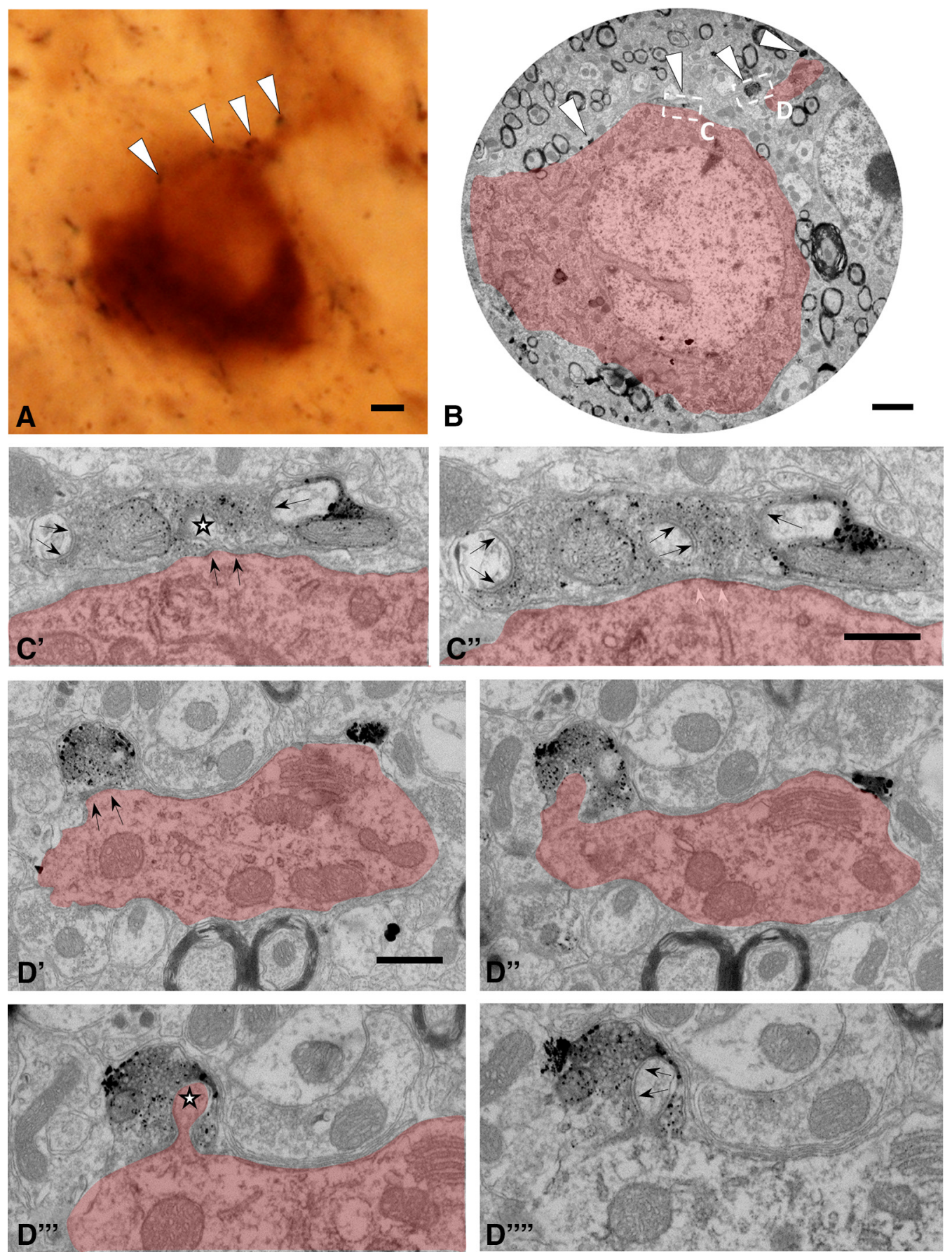

Figure 6. GLYT2-IR axon terminals synapse with somatic (C) and dendritic (D) spines of cholinergic neurons in the HDB. $A$, High-power micrograph of the immunohistochemically double labeled and epoxy-embedded section shows multiple contacts (arrowheads) between GLYT2-IR axon varicosities and a ChAT-IR neurons (highlighted in red). $\boldsymbol{B}-\boldsymbol{D}^{\prime \prime \prime \prime}$, The outlined areas (labeled with $\left(\right.$ and $D$ ) of the low-power electron micrograph are shown in further magnified images of consecutive ultrathin sections ( $\left.\boldsymbol{C}^{\prime}-\mathbf{D}^{\prime \prime \prime \prime}\right)$. Dendritic spines are embedded in and synapsing (black arrows) with GLYT2-IR axon terminals; the spine neck identifies the dendritic spine (stars) in connection with the ChAT-IR neuron. Scale bars: $\boldsymbol{A}, 5 \mu \mathrm{m} ; \boldsymbol{B}, 2 \mu \mathrm{m} ; \boldsymbol{C}^{\prime}-\boldsymbol{D}^{\prime \prime \prime \prime}, 500 \mathrm{~nm}$.

of the events, these IPSCs were very likely chloride currents, as they were clearly distinguished from potassium currents and mixed cationic conductances. Although a slight difference in the frequency range of IPSCs could be observed in dorsomedially versus ventrolaterally distributed cells, the frequent appearance of cholinergic neurons showing pan-GlyR $\alpha$ immunoreactivity or a close relationship with GLYT1 or GLYT2-IR cell processes indicates a nonselective, general role for glycine in all major subdivisions of the BF. However, these do not exclude the possibility of prevailing differences within glycinergic input of specific cho- linergic cell populations. For example, EF and LF cholinergic neurons were distinguished (Unal et al., 2012) with putative functional consequences. It was suggested, that the EF neurons are more suitable for phasic changes in acetylcholine release associated with attention, and the late firing neurons could support general arousal by maintaining tonic acetylcholine levels. Comparison of the glycinergic sIPSCs of these subtypes in the current study revealed a significantly higher amplitude and longer decay time in EF than in LF neurons, indicating a potential difference in the somatodendritic, proximodistal location of their glycinergic 

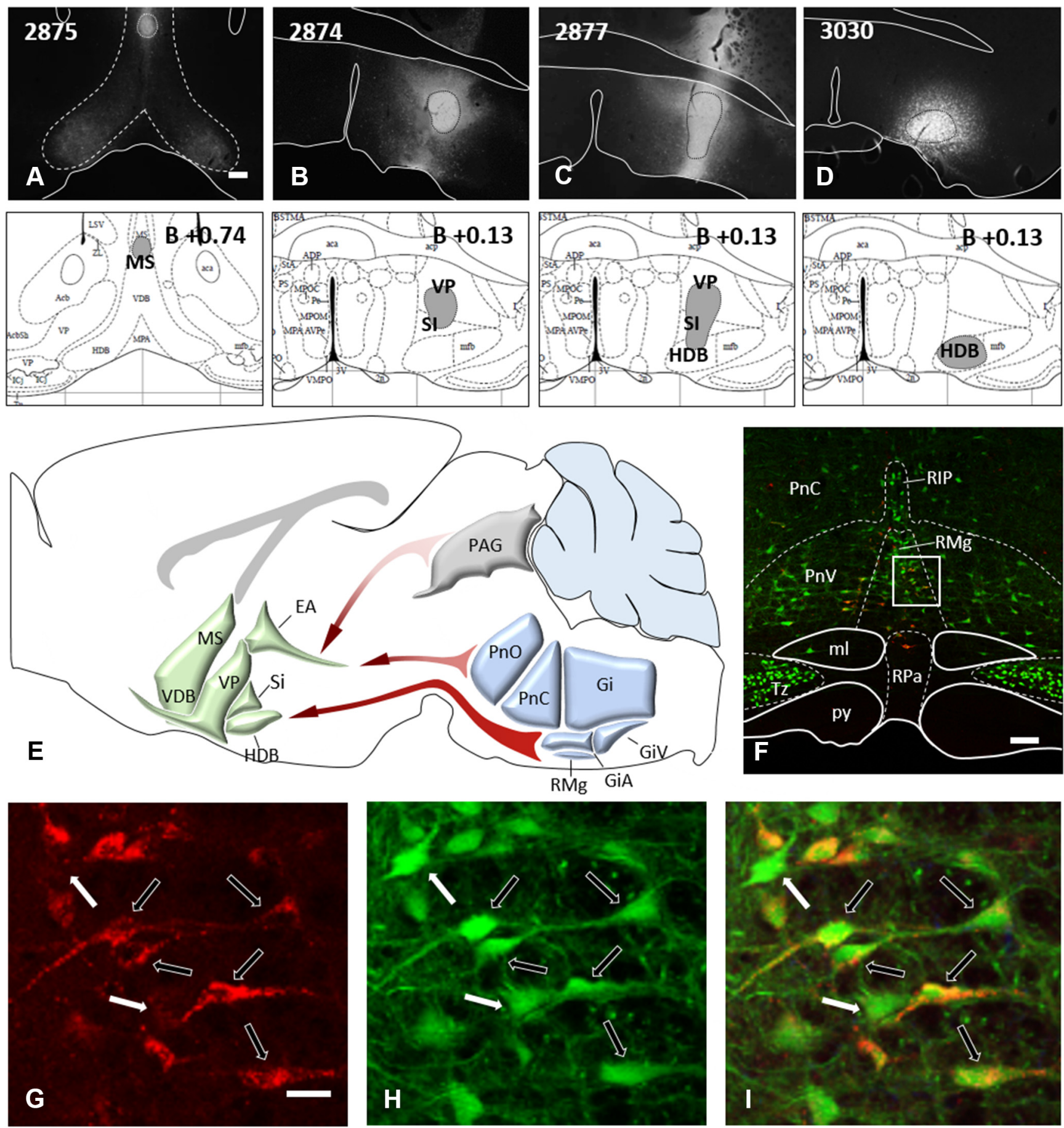

Figure 7. Location of basal forebrain-projecting glycinergic neurons revealed by iontophoretic injection of the retrograde tracer CTB or Fluoro-Gold into different subdivisions of the BF. A-D, Representative CTB-IR (\#2875, \#2874, and \#2877) and Fluoro-Gold (\#3030) injection sites plotted in basal forebrain section images and the corresponding atlas figures (based on Paxinos, 2013). $\boldsymbol{E}$, General overview of glycinergic projections from the brainstem to basal forebrain showing the most abundant input from the raphe magnus and its neighboring nuclei (red arrow) and the least number of retrogradely labeled cells locating in the periaqueductal gray matter (PAG; light red arrow). $\boldsymbol{F}$, Retrogradely labeled cells detected in the pons, containing GLYT2-GFP-expressing cells in the raphe magnus nucleus (RMg), pontine reticular nucleus ventral part $(\mathrm{PnV})$ and caudal part $(\mathrm{PnC})$, and raphe interpositus nucleus (RIP). The outlined area is further magnified in $\mathrm{G}-\mathrm{I}$ to demonstrate double-labeled neurons projecting to the BF. $\mathbf{G}-\boldsymbol{I}$, The single-labeled (white arrow) and double-labeled cells (black arrows) are shown in corresponding single $(\boldsymbol{G}, \boldsymbol{H})$ and dual $(\boldsymbol{I})$ color images. Gi, Gigantocellular reticular nucleus; GiA, gigantocellular reticular nucleus, $\alpha$ part; GiV, gigantocellular reticular nucleus, ventral; Pn0, pontine reticular nucleus, oral part; py, pyramidal tract; Rpa, raphe pallidus nucleus; Tz, nucleus of the trapezoid body. Scale bars: $A-D, F, 100 \mu \mathrm{m} ; \mathbf{G}-I, 25 \mu \mathrm{m}$.

synapses or in the general membrane properties determining propagation characteristics of IPSCs. The responses of EF and LF cholinergic neurons to glycine raise a possibility for the involvement of this inhibitory neurotransmitter in both attention regulation and arousal.
Origin of glycine input and putative colocalization with GABA

The BF does not contain glycinergic neurons; they are primarily located in the brainstem and spinal cord. Only the axonal projections reach the forebrain areas, as was shown in transgenic ani- 

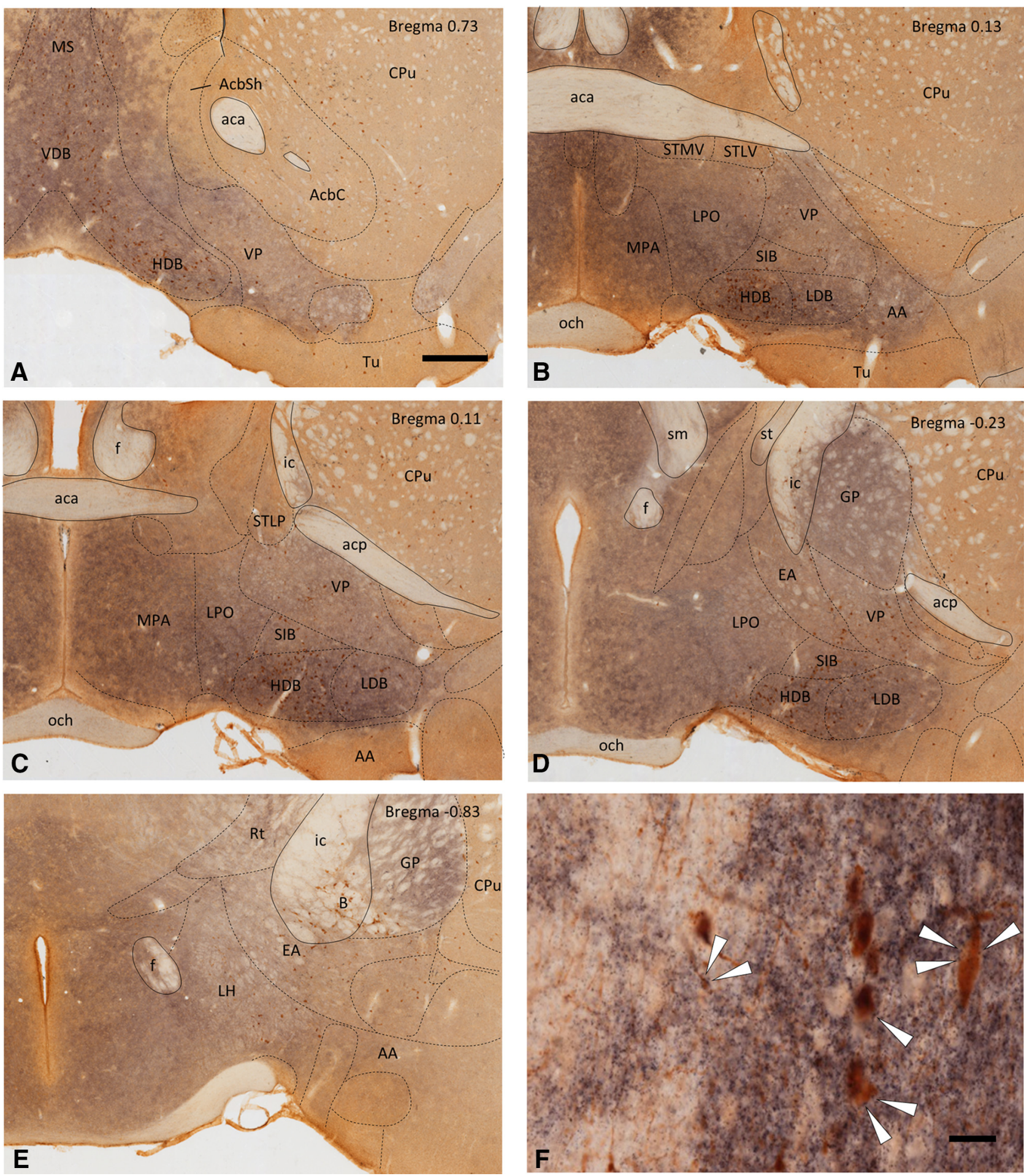

Figure 8. Dual immunohistochemical labeling of GLYT1-IR structures (arrowheads) in the vicinity of ChAT-IR neurons. A-E, Distribution of GLYT1- and ChAT-IR cellular profiles in the basal forebrain shown in coronal sections at five different rostrocaudal levels. Cholinergic neurons are embedded in GLYT1-IR puncta present in all major regions of the basal forebrain. The rostrocaudal levels are given in millimeters from the bregma, based upon the mouse brain atlas (Paxinos, 2013). $\boldsymbol{F}$, The medium power reveals a patchy arrangement of GLYT1-IR puncta resembling the shape of astrocytes. Many IR puncta are in close vicinity to ChAT-IR neurons (arrowheads). st, Stria terminalis; STLP, bed nucleus of the stria terminalis, lateral division, posterior part; STLV, bed nucleus of the stria terminalis, lateral division, ventral part; STMV, bed nucleus of the stria terminalis, medial division, ventral part. Scale bars: $\boldsymbol{A}-\boldsymbol{E}, 500 \mu \mathrm{m} ; \boldsymbol{F}, 50 \mu \mathrm{m}$. Contrast and brightness were adjusted by the Curves function of Adobe Photoshop 5.1.

mals expressing GFP under the control of GLYT2 promoter (Zeilhofer et al., 2005). In the current study, the same animal model was used to localize the glycinergic neurons projecting to the BF. Relatively few areas in the brainstem were found to exhibit cells double labeled for GFP and the retrograde tracer CTB subunit or Fluoro-Gold. The majority of glycine-containing projecting neurons were found in the nucleus raphe magnus and the gigantocellular reticular nucleus. These nuclei have been reported to establish a descending pathway responsible for muscle atonia during REM sleep (Holstege and Bongers, 1991; Kato et 

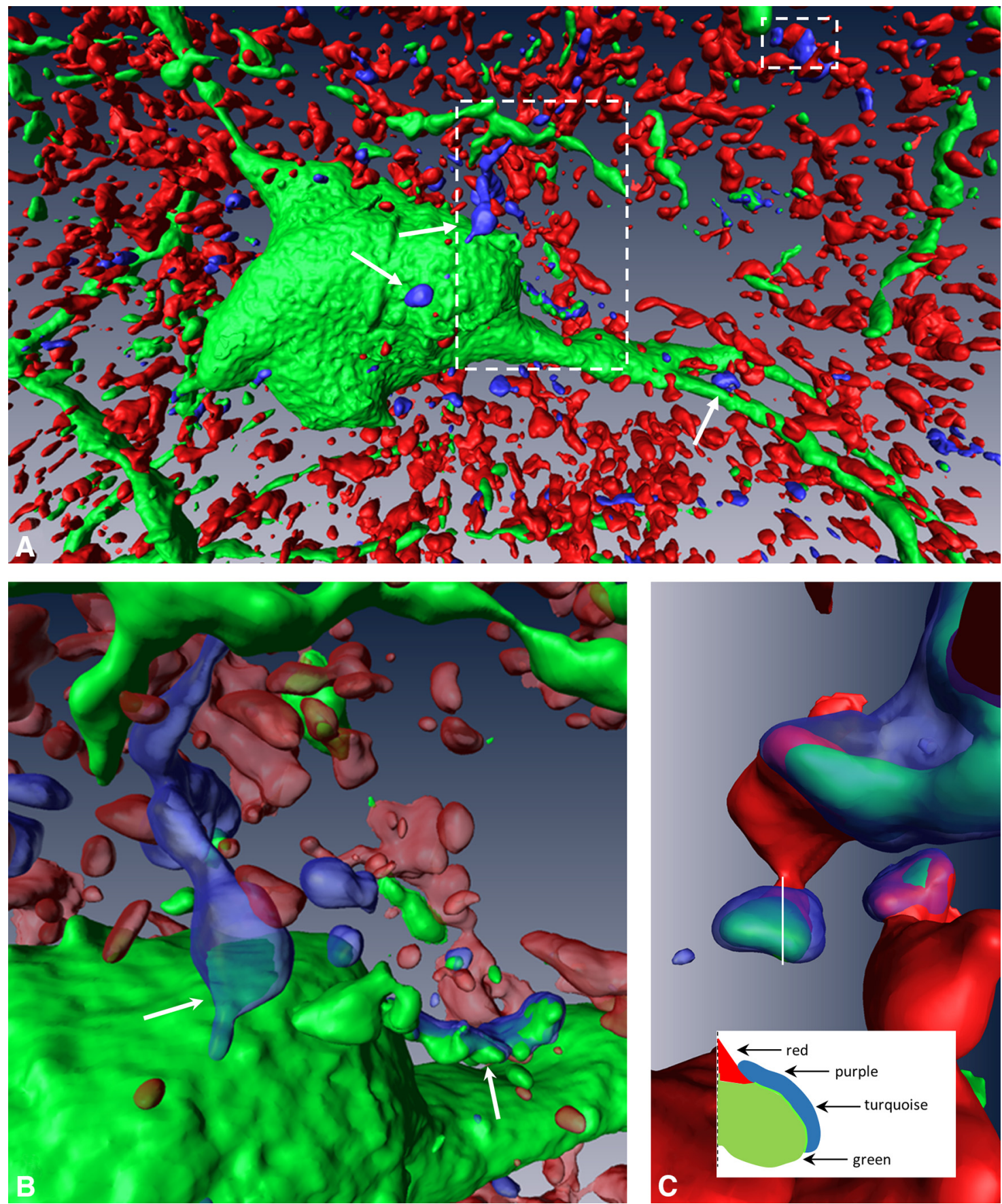

Figure 9. 3D reconstruction from the confocal image of neural structures in a section immunohistochemically labeled for ChAT (green), GLYT1 (red), and GLYT2 (blue). $A$, GLYT2-IR varicose processes are in apposition to the ChAT-IR cell body or processes (arrows). GLYT1-positive elements become associated with surface areas of ChAT-IR neurons, including areas near apposing GLYT2-IR terminals. $\boldsymbol{B}, \boldsymbol{C}$, The outlined areas are further magnified and rotated in $\boldsymbol{B}$ and $\boldsymbol{C}$. In addition, the GLYT2-IR processes are made semitransparent to demonstrate apposing surfaces. The inset in $\boldsymbol{C}$ shows the overlapping structures from the side and the color generated by the differently labeled processes at the white line.

al., 2006). Although the projection of GABA/glycinergic neurons from these nuclei to the spinal cord has been demonstrated, recent findings emphasize the primary role of glutamatergic neurons in these nuclei in indirectly inhibiting the motoneurons via spinal cord interneurons during REM sleep (Vetrivelan et al., 2009). Further studies are required to clarify the function of the ascending glycinergic pathways from these REM sleep-active nuclei to the BF. It would be interesting to find out whether bifurcating collaterals of the same cell bodies project to the spinal cord and BF cholinergic neurons, as such a scenario was implicitly suggested by demonstrating bifurcating axons orig- inating from cell bodies in the pontine reticular formation reaching the anterior horn of the spinal cord and the hypothalamus using the classical Golgi technique (Scheibel, 1958). During embryonic development, nearly all inhibitory neurons in caudal brain regions express GLYT2, indicating that glycinergic neurons are capable of coreleasing GABA. After birth, the level of cotransmission falls but still remains at $\sim 40 \%$ in adulthood (Rahman et al., 2015). It remains to be determined whether glycinergic neurons projecting to the BF contain GABA in their axons, since a mixed glycinergic/GABAergic input and cell-specific expression of glycine receptors and 

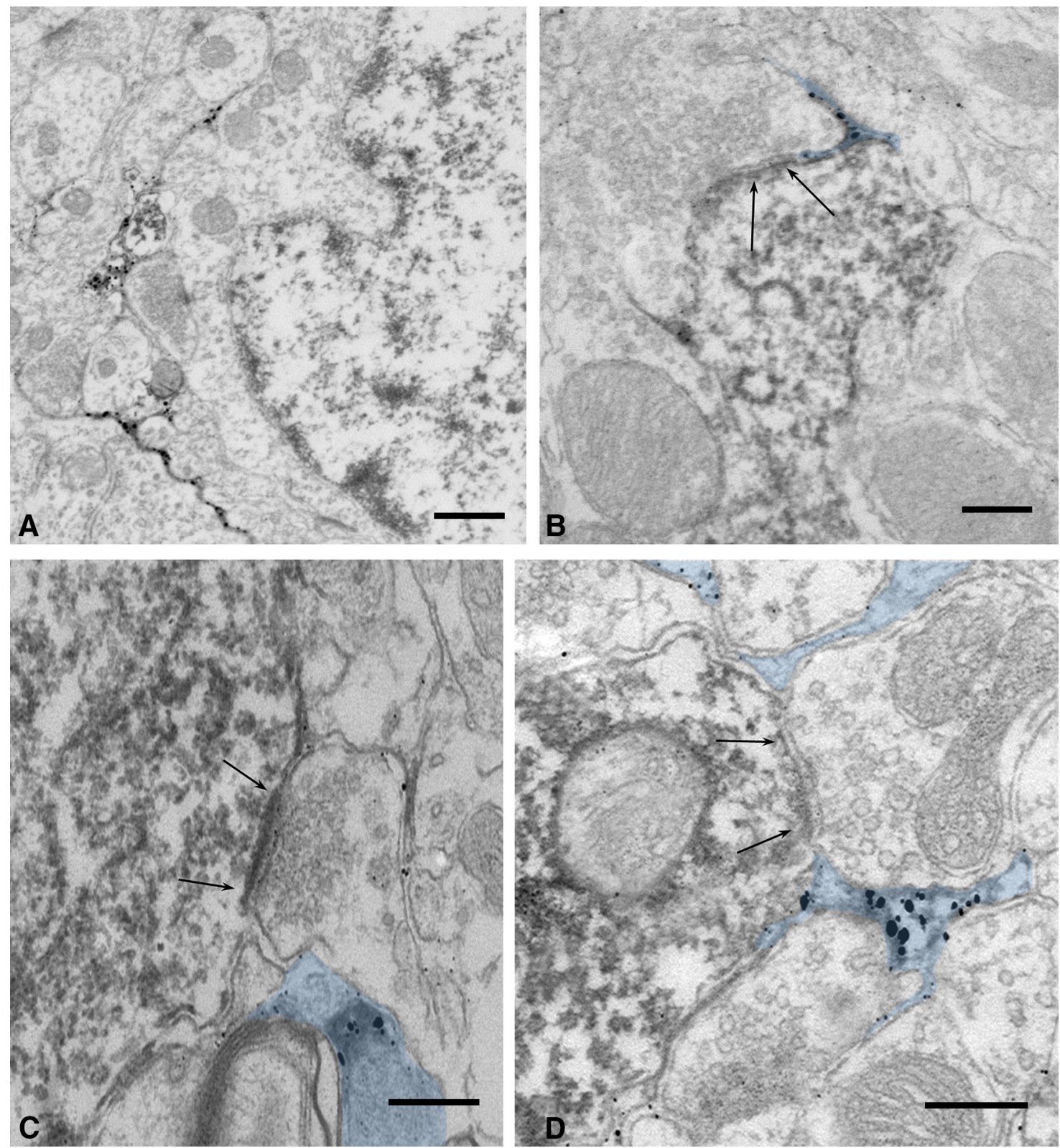

Figure 10. $A-D$, Electron microscopic images of thin GLYT1-IR astrocytic processes (labeled with silver-gold particles) in the vicinity of nonlabeled neurons $(\boldsymbol{A})$ and $C h A T-I R$ neurons (labeled with DAB; $\boldsymbol{B}-\boldsymbol{D})$. The GLYT1-IR processes (highlighted in blue) appear adjacent to nonlabeled axon terminals synapsing (arrows) with a (hAT-IR perikaryon $(\boldsymbol{C})$ or dendrite $(\boldsymbol{B}, \boldsymbol{D})$. Scale bars, $\boldsymbol{A}, 1 \mu \mathrm{m} ; \boldsymbol{B}-\boldsymbol{D}, 250 \mathrm{~nm}$.

$\mathrm{GABA}_{\mathrm{A}}$ receptors would indicate the capability for cholinergic neurons to shape their inhibitory control.

\section{Functional considerations}

GLYT2-IR axon terminals were found on ChAT-IR perikarya, as well as smaller- and larger-diameter cholinergic dendrites, including spines on both the soma and dendrites of cholinergic neurons. Inhibitory synapses often appear on the soma and the proximal dendrites of target cells, in a position to efficiently block the generation of action potentials. Their presence on more distal dendritic branches, which was frequently found in the current study, was indicated to exert a less powerful but still significant inhibitory influence on target cells, involving plasticity (Chiu et al., 2013). Spine-like processes were observed in most biocytinfilled mouse cholinergic neurons (Fig. $2 F$ ) and can also be demonstrated in juxtacellularly filled or immunostained rat BFC neurons at the ultrastructural level (A. Duque and L. Zaborszky, unpublished observation). It remains to be determined whether glycinergic synapses detected on the spines of the soma and the proximal dendrites (Fig. 6) counterbalance excitatory inputs impinging on adjacent dendritic segments. Spine morphology and synaptic plasticity are regulated by the cytoskeletal and scaffolding protein actin (dos Remedios et al., 2003), and its dysfunction is thought to be critical in amyloid $\beta$-induced cholinergic cell loss in Alzheimer's disease (Song et al., 2002; Maloney et al., 2005). Organophosphate insecticides were shown to induce a concentrationdependent reduction of spine-like processes in BFC neurons (Del Pino et al., 2016), which is accompanied by the alteration of NMDA receptors. Unbalanced NMDA receptor-mediated signaling results in cognitive and memory dysfunctions, and it is supposedly the leading pathological process in many neurological and neurodegenerative diseases (Gu et al., 2014). 
It seems that either hyperfunction or hypofunction of this receptor can evoke glutamate toxicity in vulnerable parts of the CNS (Newcomer et al., 2000); the reason for that may be in the different signaling pathways recruited by the two major subpopulations, the synaptic and extrasynaptic pools of NMDA receptors. Although there are some contradictory data in this regard, the apparent agreement is that in addition to the physiological signaling, glutamatergic transmission via synaptic NMDA receptors is neuroprotective, whereas transmission via nonsynaptic NMDA receptors is excitotoxic (Papouin et al., 2012). Glycine is also a coagonist on NMDA receptors, although D-serine released by astrocytes can also occupy the glycine-binding site on the NMDA receptors. However, D-serine acts at synaptic NMDA receptors and glycine acts as their extrasynaptic counterparts ( $\mathrm{Pa}-$ pouin et al., 2012). The high level of GLYT1 in BF (Fig. 10; Kalló et al., 2008) suggests a very tight control on the extracellular levels of the coagonist glycine. It still needs to be clarified whether glycine influences NMDA-mediated currents on cholinergic neurons and thereby contributes to BF plasticity and learning.

\section{Concluding remarks}

In summary, the detection of (1) a rich network of glycinergic axons in connection with the cholinergic neurons in the different subregions of the BF; (2) symmetric glycinergic synapses on the perikaryon and both the proximal and distal dendritic branches of BFC neurons; and (3) bicuculline-resistant, strychnine-sensitive postsynaptic events indicate a general inhibitory role for glycine in the regulation of $\mathrm{BFC}$ functions. It remains for future studies to explore whether specific behavioral conditions are linked with glycine release in the BF and whether glycine could act as a modulator of NMDA receptor functions and thus could contribute to the vulnerability of cholinergic neurons in Alzheimer's disease or related neurodegenerative diseases.

\section{References}

Anaclet C, Ferrari L, Arrigoni E, Bass CE, Saper CB, Lu J, Fuller PM (2014) The GABAergic parafacial zone is a medullary slow wave sleep-promoting center. Nat Neurosci 17:1217-1224. CrossRef Medline

Anaclet C, Pedersen NP, Ferrari LL, Venner A, Bass CE, Arrigoni E, Fuller PM (2015) Basal forebrain control of wakefulness and cortical rhythms. Nat Commun 6:8744. CrossRef Medline

Bardóczi Z, Watanabe M, Zaborszky L, Liposits Z, Kalló I (2013) Morphological evidence for direct glycinergic input to cholinergic neurons in the mouse basal forebrain. Soc Neurosci Abstr 39:222.08.

Buzsaki G, Bickford RG, Ponomareff G, Thal LJ, Mandel R, Gage FH (1988) Nucleus basalis and thalamic control of neocortical activity in the freely moving rat. J Neurosci 8:4007-4026. Medline

Chiu CQ, Lur G, Morse TM, Carnevale NT, Ellis-Davies GC, Higley MJ (2013) Compartmentalization of GABAergic inhibition by dendritic spines. Science 340:759-762. CrossRef Medline

Datta S, Maclean RR (2007) Neurobiological mechanisms for the regulation of mammalian sleep-wake behavior: reinterpretation of historical evidence and inclusion of contemporary cellular and molecular evidence. Neurosci Biobehav Rev 31:775-824. CrossRef Medline

Del Pino J, Moyano P, Anadon MJ, Garcia JM, Diaz MJ, Gomez G, Garcia J, Frejo MT (2016) SN56 basal forebrain cholinergic neuronal loss after acute and long-term chlorpyrifos exposure through oxidative stress generation; P75(NTR) and alpha7-nAChRs alterations mediated partially by AChE variants disruption. Toxicology 353-354:48-57. CrossRef Medline

dos Remedios CG, Chhabra D, Kekic M, Dedova IV, Tsubakihara M, Berry DA, Nosworthy NJ (2003) Actin binding proteins: regulation of cytoskeletal microfilaments. Physiol Rev 83:433-473. CrossRef Medline

Eulenburg V, Armsen W, Betz H, Gomeza J (2005) Glycine transporters: essential regulators of neurotransmission. Trends Biochem Sci 30:325333. CrossRef Medline

Fuller PM, Fuller P, Sherman D, Pedersen NP, Saper CB, Lu J (2011) Reassessment of the structural basis of the ascending arousal system. J Comp Neurol 519:933-956. CrossRef Medline
Gaykema RP, Zaborszky L (1997) Parvalbumin-containing neurons in the basal forebrain receive direct input from the substantia nigra-ventral tegmental area. Brain Res 747:173-179. CrossRef Medline

Giber K, Diana MA, Plattner V, Dugué GP, Bokor H, Rousseau CV, Maglóczky Z, Havas L, Hangya B, Wildner H, Zeilhofer HU, Dieudonné S, Acsády L (2015) A subcortical inhibitory signal for behavioral arrest in the thalamus. Nat Neurosci 18:562-568. CrossRef Medline

Gomeza J, Ohno K, BetzH (2003) Glycine transporter isoforms in the mammalian central nervous system: structures, functions and therapeutic promises. Curr Opin Drug Discov Dev 6:675-682. CrossRef

Gu Z, Yakel JL (2011) Timing-dependent septal cholinergic induction of dynamic hippocampal synaptic plasticity. Neuron 71:155-165. CrossRef Medline

Gu Z, Cheng J, Zhong P, Qin L, Liu W, Yan Z (2014) Abeta selectively impairs mGluR7 modulation of NMDA signaling in basal forebrain cholinergic neurons: implication in Alzheimer's disease. J Neurosci 34:1361413628. CrossRef Medline

Hajszán T, Zaborszky L (2002) Direct catecholaminergic-cholinergic interactions in the basal forebrain. III. Adrenergic innervation of choline acetyltransferase-containing neurons in the rat. J Comp Neurol 449:141157. CrossRef Medline

Holstege JC, Bongers CM (1991) A glycinergic projection from the ventromedial lower brainstem to spinal motoneurons. An ultrastructural double labeling study in rat. Brain Res 566:308-315. CrossRef Medline

Hondo M, Furutani N, Yamasaki M, Watanabe M, Sakurai T (2011) Orexin neurons receive glycinergic innervations. PLoS One 6:e25076. CrossRef Medline

Jo S, Kalló I, Bardóczi Z, Arrojo e Drigo R, Zeöld A, Liposits Z, Oliva A, Lemmon VP, Bixby JL, Gereben B, Bianco AC (2012) Neuronal hypoxia induces Hsp40-mediated nuclear import of type 3 deiodinase as an adaptive mechanism to reduce cellular metabolism. J Neurosci 32:8491-8500. CrossRef Medline

Kalló I, Butler JA, Barkovics-Kalló M, Goubillon ML, Coen CW (2001) Oestrogen receptor beta-immunoreactivity in gonadotropin releasing hormone-expressing neurones: regulation by oestrogen. J Neuroendocrinol 13:741-748. Medline

Kalló I, Jekkel C, Hrabovszky E, Jurányi Z, Vida B, Járási A, Wilheim T, Harsing LG Jr, Liposits Z (2008) Immunohistochemical and in situ hybridization studies on glycine transporter 1 after transient ischemia in the rat forebrain. Neurochem Int 52:799-808. CrossRef Medline

Kandel ER, Schwartz JH, Jessel TM, Siegelbaum SA, Hudspeth AJ (2013) Principles of neural science, Ed 5. New York: McGraw-Hill.

Kato G, Yasaka T, Katafuchi T, Furue H, Mizuno M, Iwamoto Y, Yoshimura M (2006) Direct GABAergic and glycinergic inhibition of the substantia gelatinosa from the rostral ventromedial medulla revealed by in vivo patch-clamp analysis in rats. J Neurosci 26:1787-1794. CrossRef Medline

Kaur S, Pedersen NP, Yokota S, Hur EE, Fuller PM, Lazarus M, Chamberlin NL, Saper CB (2013) Glutamatergic signaling from the parabrachial nucleus plays a critical role in hypercapnic arousal. J Neurosci 33:7627-7640. CrossRef Medline

Kim T, Thankachan S, McKenna JT, McNally JM, Yang C, Choi JH, Chen L, Kocsis B, Deisseroth K, Strecker RE, Basheer R, Brown RE, McCarley RW (2015) Cortically projecting basal forebrain parvalbumin neurons regulate cortical gamma band oscillations. Proc Natl Acad Sci U S A 112:35353540. CrossRef Medline

Liposits Z, Sétáló G, Flerkó B (1984) Application of the silver-gold intensified 3,3'-diaminobenzidine chromogen to the light and electron microscopic detection of the luteinizing hormone-releasing hormone system of the rat brain. Neuroscience 13:513-525. CrossRef Medline

Liposits Z, Sherman D, Phelix C, Paull WK (1986) A combined light and electron microscopic immunocytochemical method for the simultaneous localization of multiple tissue antigens. Tyrosine hydroxylase immunoreactive innervation of corticotropin releasing factor synthesizing neurons in the paraventricular nucleus of the rat. Histochemistry 85:95-106. CrossRef Medline

Luppi PH, Clément O, Valencia Garcia S, Brischoux F, Fort P (2013) New aspects in the pathophysiology of rapid eye movement sleep behavior disorder: the potential role of glutamate, gamma-aminobutyric acid, and glycine. Sleep Med 14:714-718. CrossRef Medline

Madisen L, Zwingman TA, Sunkin SM, Oh SW, Zariwala HA, Gu H, Ng LL, Palmiter RD, Hawrylycz MJ, Jones AR, Lein ES, Zeng H (2010) A robust 
and high-throughput Cre reporting and characterization system for the whole mouse brain. Nat Neurosci 13:133-140. CrossRef Medline

Maloney MT, Minamide LS, Kinley AW, Boyle JA, Bamburg JR (2005) $\beta$-secretase-cleaved amyloid precursor protein accumulates at actin inclusions induced in neurons by stress or amyloid beta: a feedforward mechanism for Alzheimer's disease. J Neurosci 25:11313-11321. CrossRef Medline

Mesulam MM, Mufson EJ, Wainer BH, Levey AI (1983) Central cholinergic pathways in the rat: an overview based on an alternative nomenclature (Ch1-Ch6). Neuroscience 10:1185-1201. CrossRef Medline

Moruzzi G, Magoun HW (1949) Brain stem reticular formation and activation of the EEG. Electroencephalogr Clin Neurophysiol 1:455-473. CrossRef Medline

Motts SD, Slusarczyk AS, Sowick CS, Schofield BR (2008) Distribution of cholinergic cells in guinea pig brainstem. Neuroscience 154:186-195. CrossRef Medline

Nauta WJH, Kuypers HGJM (1957) Some ascending pathways in the brain stem reticular formation. Boston: Little, Brown.

Newcomer JW, Farber NB, Olney JW (2000) NMDA receptor function, memory, and brain aging. Dialogues Clin Neurosci 2:219-232. Medline

Papouin T, Ladépêche L, Ruel J, Sacchi S, Labasque M, Hanini M, Groc L, Pollegioni L, Mothet JP, Oliet SH (2012) Synaptic and extrasynaptic NMDA receptors are gated by different endogenous coagonists. Cell 150: 633-646. CrossRef Medline

Paxinos GF, K. B (2013) The mouse brain in stereotaxic coordinates, Ed 4. San Diego: Elsevier.

Rahman J, Besser S, Schnell C, Eulenburg V, Hirrlinger J, Wojcik SM, Hülsmann S (2015) Genetic ablation of VIAAT in glycinergic neurons causes a severe respiratory phenotype and perinatal death. Brain Struct Funct 220:2835-2849. CrossRef Medline

Rossi J, Balthasar N, Olson D, Scott M, Berglund E, Lee CE, Choi MJ, Lauzon D, Lowell BB, Elmquist JK (2011) Melanocortin-4 receptors expressed by cholinergic neurons regulate energy balance and glucose homeostasis. Cell Metab 13:195-204. CrossRef Medline

Saper CB, Cano G, Scammell TE (2005) Homeostatic, circadian, and emotional regulation of sleep. J Comp Neurol 493:92-98. CrossRef Medline

Scheibel MES, A.B (1958) Structural substrates for integrative patterns in the brain stem reticular core. In: Reticular formation of the brain (Jasper HH, Proctor LD, Knighton RS, Noshay WC, Costello RT, eds), pp 31-55. Boston: Little, Brown

Schmued LC, Fallon JH (1986) Fluoro-Gold: a new fluorescent retrograde axonal tracer with numerous unique properties. Brain Res 377:147-154. CrossRef Medline
Song C, Perides G, Wang D, Liu YF (2002) beta-Amyloid peptide induces formation of actin stress fibers through p38 mitogen-activated protein kinase. J Neurochem 83:828-836. CrossRef Medline

Sotty F, Danik M, Manseau F, Laplante F, Quirion R, Williams S (2003) Distinct electrophysiological properties of glutamatergic, cholinergic and GABAergic rat septohippocampal neurons: novel implications for hippocampal rhythmicity. J Physiol 551:927-943. CrossRef Medline

Steriade M, Timofeev I (2002) Generators of ictal and interictal electroencephalograms associated with infantile spasms: intracellular studies of cortical and thalamic neurons. Int Rev Neurobiol 49:77-98. CrossRef Medline

Sutcliffe JG, de Lecea L (2002) The hypocretins: setting the arousal threshold. Nat Rev Neurosci 3:339-349. CrossRef Medline

Unal CT, Golowasch JP, Zaborszky L (2012) Adult mouse basal forebrain harbors two distinct cholinergic populations defined by their electrophysiology. Front Behav Neurosci 6:21. CrossRef Medline

Vetrivelan R, Fuller PM, Tong Q, Lu J (2009) Medullary circuitry regulating rapid eye movement sleep and motor atonia. J Neurosci 29:9361-9369. CrossRef Medline

Wu M, Zaborszky L, Hajszan T, van den Pol AN, Alreja M (2004) Hypocretin/orexin innervation and excitation of identified septohippocampal cholinergic neurons. J Neurosci 24:3527-3536. CrossRef Medline

Xu M, Chung S, Zhang S, Zhong P, Ma C, Chang WC, Weissbourd B, Sakai N, Luo L, Nishino S, Dan Y (2015) Basal forebrain circuit for sleep-wake control. Nat Neurosci 18:1641-1647. CrossRef Medline

Zaborszky L, Duque A (2003) Sleep-wake mechanisms and basal forebrain circuitry. Front Biosci 8:d1146-d1169. Medline

Záborszky L, Cullinan WE, Luine VN (1993) Catecholaminergic-cholinergic interaction in the basal forebrain. Prog Brain Res 98:31-49. CrossRef Medline

Zaborszky L, Pang K, Somogyi J, Nadasdy Z, Kallo I (1999) The basal forebrain corticopetal system revisited. Ann N Y Acad Sci 877:339-367. CrossRef Medline

Zaborszky L, Csordas A, Mosca K, Kim J, Gielow MR, Vadasz C, Nadasdy Z (2015) Neurons in the basal forebrain project to the cortex in a complex topographic organization that reflects corticocortical connectivity patterns: an experimental study based on retrograde tracing and 3D reconstruction. Cereb Cortex 25:118-137. CrossRef Medline

Zeilhofer HU, Studler B, Arabadzisz D, Schweizer C, Ahmadi S, Layh B, Bös MR, Fritschy JM (2005) Glycinergic neurons expressing enhanced green fluorescent protein in bacterial artificial chromosome transgenic mice. J Comp Neurol 482:123-141. CrossRef Medline 